\title{
Asymmetric Multimetallic Mesoporous Nanospheres
}

Hao Lv, ${ }^{1,+}$ Dongdong Xu,${ }^{1,+}$ Lizhi Sun, ${ }^{1}$ Joel Henzie, ${ }^{2,3}$ Aaron Lopes, ${ }^{4}$ Qingyu Gu, ${ }^{1}$ Yusuke Yamauchi, $, 2,5,6$ and Ben Liu',*

${ }^{1}$ Jiangsu Key Laboratory of New Power Batteries, Jiangsu Collaborative Innovation Center of Biomedical Functional Materials, School of Chemistry and Materials Science, Nanjing Normal University, Nanjing 210023, China

${ }^{+}$H.L. and D.X. contributed equally to this work.

*E-mail: ben.liu@njnu.edu.cn

${ }^{2}$ Key Laboratory of Eco-chemical Engineering, College of Chemistry and Molecular Engineering, Qingdao University of Science and Technology, Qingdao 266042, China

${ }^{3}$ International Center for Materials Nanoarchitectonics (WPI-MANA), National Institute for Materials

Science (NIMS), 1-1 Namiki, Tsukuba, Ibaraki 305-0044, Japan

${ }^{4}$ Department of Chemical Engineering, Massachusetts Institute of Technology, Cambridge, Massachusetts 02139, United States

${ }^{5}$ School of Chemical Engineering and Australian Institute for Bioengineering and Nanotechnology (AIBN), The University of Queensland, Brisbane, QLD 4072, Australia

${ }^{6}$ Department of Plant \& Environmental New Resources, Kyung Hee University, 1732 Deogyeong-daero, Giheung-gu, Yongin-si, Gyeonggi-do 446-701, South Korea 


\section{Chemicals and Materials}

Palladium(II) chloride $\left(\mathrm{PdCl}_{2}\right)$, Chloroplatinic acid $\left(\mathrm{H}_{2} \mathrm{PtCl}_{6}\right)$, chloroauric acid $\left(\mathrm{HAuCl}_{4}\right)$, silver nitrate $\left(\mathrm{AgNO}_{3}\right)$, copper nitrate $\left(\mathrm{Cu}\left(\mathrm{NO}_{3}\right)_{2}\right)$, Iron(III) nitrate $\left(\mathrm{Fe}\left(\mathrm{NO}_{3}\right)_{3}\right)$, commercial palladium black $(\mathrm{PdB})$ nanoparticles, dioctadecyldimethylammonium chloride (DODAC), cetyltrimethylammonium chloride $\left(\mathrm{C}_{16} \mathrm{TAC}\right)$, sodium dodecyl sulfate $(\mathrm{SDS})$, Pluronic $\mathrm{F} 127$, hydrazine $\left(\mathrm{N}_{2} \mathrm{H}_{4}\right)$, sodium hypophosphite $\left(\mathrm{NaH}_{2} \mathrm{PO}_{2}\right)$, L-ascorbic acid (AA), and sodium borohydride $\left(\mathrm{NaBH}_{4}\right)$ were purchased from Alfa Aesar. Nafion solution was obtained from Sigma Aldrich. Hydrochloric acid $(\mathrm{HCl})$, potassium hydroxide $(\mathrm{KOH})$, and sodium hydroxide $(\mathrm{NaOH})$ were obtained from Sinopharm Chemical Reagent Co. Ltd. (Shanghai). $10 \mathrm{mM} \mathrm{H}_{2} \mathrm{PdCl}_{4}$ solution was prepared by dissolving $0.355 \mathrm{~g}$ of palladium (II) chloride into $20 \mathrm{~mL}$ of 0.2 $\mathrm{M} \mathrm{HCl}$ solution and further diluting with $180 \mathrm{~mL}$ of deionized $\mathrm{H}_{2} \mathrm{O}$. All the reagents are of analytical reagent grade and used without further purification. Deionized $\mathrm{H}_{2} \mathrm{O}$ with the resistivity of $18.25 \mathrm{~m} \Omega$ was used in all experiments.

\section{Synthesis of asymmetric BMSs}

Trimetallic PdAgCu asymmetric BMSs were synthesized with a one-pot solution-phase route at room temperature $\left(25^{\circ} \mathrm{C}\right)$, in which DODAC, $\mathrm{H}_{2} \mathrm{PdCl}_{4}, \mathrm{AgNO}_{3}$ and $\mathrm{Cu}\left(\mathrm{NO}_{3}\right)_{2}$, and $\mathrm{AA}$ were used as the "dual" template surfactant, metal precursors, and reducing agent, respectively. Taking PdAgCu BMS-4/8 as the example, $15 \mathrm{mg}$ of DODAC was first dissolved into $10 \mathrm{~mL}$ of $\mathrm{H}_{2} \mathrm{O}$ containing $20 \mu \mathrm{L}$ of ethanol, followed by the addition of $0.48 \mathrm{~mL}$ of $\mathrm{H}_{2} \mathrm{PdCl}_{4}$ solution $(10 \mathrm{mM})$. After stirred for $10 \mathrm{~min}, 0.24 \mathrm{~mL}$ of $\mathrm{AgNO}_{3}(10$ $\mathrm{mM})$ and $0.08 \mathrm{~mL}$ of $\mathrm{Cu}\left(\mathrm{NO}_{3}\right)_{2}(10 \mathrm{mM})$ were successively injected. The $\mathrm{pH}$ of this solution was adjusted to 7.11 . Then, $1.0 \mathrm{~mL}$ of freshly prepared AA $(0.3 \mathrm{M})$ was rapidly injected with gentle shaking. After incubated at $25^{\circ} \mathrm{C}$ for an additional $30 \mathrm{~min}$, the products were washed with acetic acid, ethanol and $\mathrm{H}_{2} \mathrm{O}$ for three times, and then freeze-dried at $-60{ }^{\circ} \mathrm{C}$ for structural and compositional characterizations and electrocatalytic tests. Similarly, surfactants, DODAC and precursor concentrations, $\mathrm{pH}$, temperatures, ethanol contents, AA contents, and Ag contents were tuned in the same synthetic conditions to tailor the $\mathrm{PdAgCu}$ nanostructures and compositions. Besides, bimetallic PdAg, trimetallic PdPtAg, tetrametallic $\mathrm{PdAgPtCu}$ and $\mathrm{PdAgCuFe} \mathrm{BMSs}$ were synthesized using the similar procedures (PdAgCu BMS-4/8) by simply changing the species of metal precursors. 


\section{Electrochemical EOR measurements}

Electrocatalytic EOR tests were performed on the $\mathrm{CHI} 660 \mathrm{E}$ electrochemical analyzer at $25{ }^{\circ} \mathrm{C}$, as described in our previous works (ACS Cent. Sci. 2018, 4, 1412; Chem. Sci. 2019, 10, 1986). A threeelectrode system was used for all electrochemical tests, in which glassy carbon electrode (GCE, 0.07065 $\mathrm{cm}^{2}$ ), carbon rod was, and saturated calomel electrode was used as the working electrode, counter electrode, and reference electrode, respectively. An ink of the nanocatalysts was prepared by mixing $1 \mathrm{mg}$ of catalysts, $4 \mathrm{mg}$ of Vulcan XC-72 carbon, $1.5 \mathrm{~mL}$ of ethanol and $0.5 \mathrm{~mL}$ of $\mathrm{H}_{2} \mathrm{O}$. After sonicating for $0.5 \mathrm{~h}, 50 \mu \mathrm{L}$ of Nafion solution ( $5 \mathrm{wt} \%$ in alcohol and $\mathrm{H}_{2} \mathrm{O}$ ) was added and further sonicated for $0.5 \mathrm{~h}$. Then, $6.0 \mu \mathrm{L}$ of above-prepared ink solution ( $3.0 \mu \mathrm{g}$ of the catalyst) was dropped on the GCE electrode and dried at $40{ }^{\circ} \mathrm{C}$ before testing. Cyclic voltammograms (CVs) were used to evaluate the electrochemical surface areas and activities of different nanocatalysts. The electrolyte solution was initially purged with $\mathrm{N}_{2}$ for 30 min before testing. Electrochemical active surface areas (ECSAs) of the Pd-based catalysts were calculated from CVs in the area of the PdO reduction peak. CO stripping tests were performed in COsaturated $\mathrm{KOH}$ solution $(1.0 \mathrm{M})$ in the potential range between -0.9 and $0.2 \mathrm{~V}$ at a scan rate of $50 \mathrm{mV} \mathrm{s}^{-1}$.

The EOR proceeds on the Pd catalyst according to the following mechanisms (Chem. Rev. 2009, 109, 4183; ACS Cent. Sci. 2018, 4, 1412):

$\mathrm{Pd}+\mathrm{CH}_{3} \mathrm{CH}_{2} \mathrm{OH}+3 \mathrm{OH}^{-} \rightarrow \mathrm{Pd}-\left(\mathrm{CH}_{3} \mathrm{CO}\right)_{a d s}+3 \mathrm{H}_{2} \mathrm{O}+3 \mathrm{e}^{-}$

$\mathrm{Pd}+\mathrm{OH}^{-} \rightarrow \mathrm{Pd}-\mathrm{OH}_{a d s}+e^{-}$

$\mathrm{Pd}-\left(\mathrm{CH}_{3} \mathrm{CO}\right)_{a d s}+\mathrm{Pd}-\mathrm{OH}_{a d s} \rightarrow \mathrm{Pd}-\mathrm{CH}_{3} \mathrm{COOH}+\mathrm{Pd}$

$\mathrm{Pd}-\mathrm{CH}_{3} \mathrm{COOH}+\mathrm{OH}^{-} \rightarrow \mathrm{Pd}+\mathrm{CH}_{3} \mathrm{COO}^{-}+\mathrm{H}_{2} \mathrm{O}$

The rate-determining step of electrochemical EOR is the oxidation/removal of poisoning carbonaceous intermediates on $\mathrm{Pd}\left(\mathrm{Pd}-\left(\mathrm{CH}_{3} \mathrm{CO}\right)_{a d s}\right)$ by adsorbed $\mathrm{OH}\left(\mathrm{OH}_{a d s}\right)$ (Equation 3). In current manuscript, we think both structural and compositional features of the PdAgCu BMSs synergistically improved the antipoisoning ability to the intermediates. On the one hand, asymmetric mesoporous nanostructures could increase the efficiency of mass transfer through the dendritic porous structures and asymmetric architecture (J. Am. Chem. Soc. 2016, 138, 11306). Meanwhile, the continuously mesoporous framework facilitates electron transfer within the nanocatalysts (Nat. Commun. 2017, 8, 15581). On the other hand, incorporation of the secondary (or tertiary) metals with Pd into multimetallic nanoalloys would facilitate the formation of $\mathrm{OH}_{\text {ads }}$ and thus accelerate the reaction between $\mathrm{M}-\mathrm{OH}_{a d s}$ and $\mathrm{Pd}-\left(\mathrm{CH}_{3} \mathrm{CO}\right)_{a d s}$ (Equation 3) (Nat. Commun. 2017, 8, 14136). Both structural and compositional merits of the PdAgCu BMSs would 
efficiently facilitate the removal of the poisoning intermediates, and eventually boosts electrochemical EOR performance kinetically.

\section{Structural and compositional characterizations}

SEM was performed using JEOL JSM-7800F with a landing energy of $5 \mathrm{kV}$. SEM samples were prepared by casting a suspension of the samples on a piece of silica wafer. TEM and HRTEM were carried out using a JEOL 2010 transmission electron microscope with an accelerating voltage of $200 \mathrm{kV}$. HAADFSTEM was taken on an FEI, Talos F200X apparatus at an accelerating voltage of $200 \mathrm{kV}$, which is equipped with STEM and EDS detectors for elemental mapping analysis. TEM and STEM samples were prepared by casting a suspension of the samples on a carbon coated nickel grid (300 mesh). Small-angle and wide-angle XRD was recorded on powder samples using a D/max $2500 \mathrm{VL} / \mathrm{PC}$ diffractometer (Japan). XPS were performed on a scanning X-ray microprobe (Thermo ESCALAB 250Xi) that uses Al Ka radiation with the binding energy of the $\mathrm{C} 1 \mathrm{~s}$ peak $(284.8 \mathrm{eV})$ as a standard. ICP-MS was recorded on NexION 350D. The Barrett-Joyner-Halenda (BJH) was analyzed with $\mathrm{N}_{2}$ adsorption/desorption isotherms, which were measured at $77 \mathrm{~K}$ using an ASAP $2010 \mathrm{M}+\mathrm{C}$ analyzer. ICP-MS was recorded on a NexION 350D. 


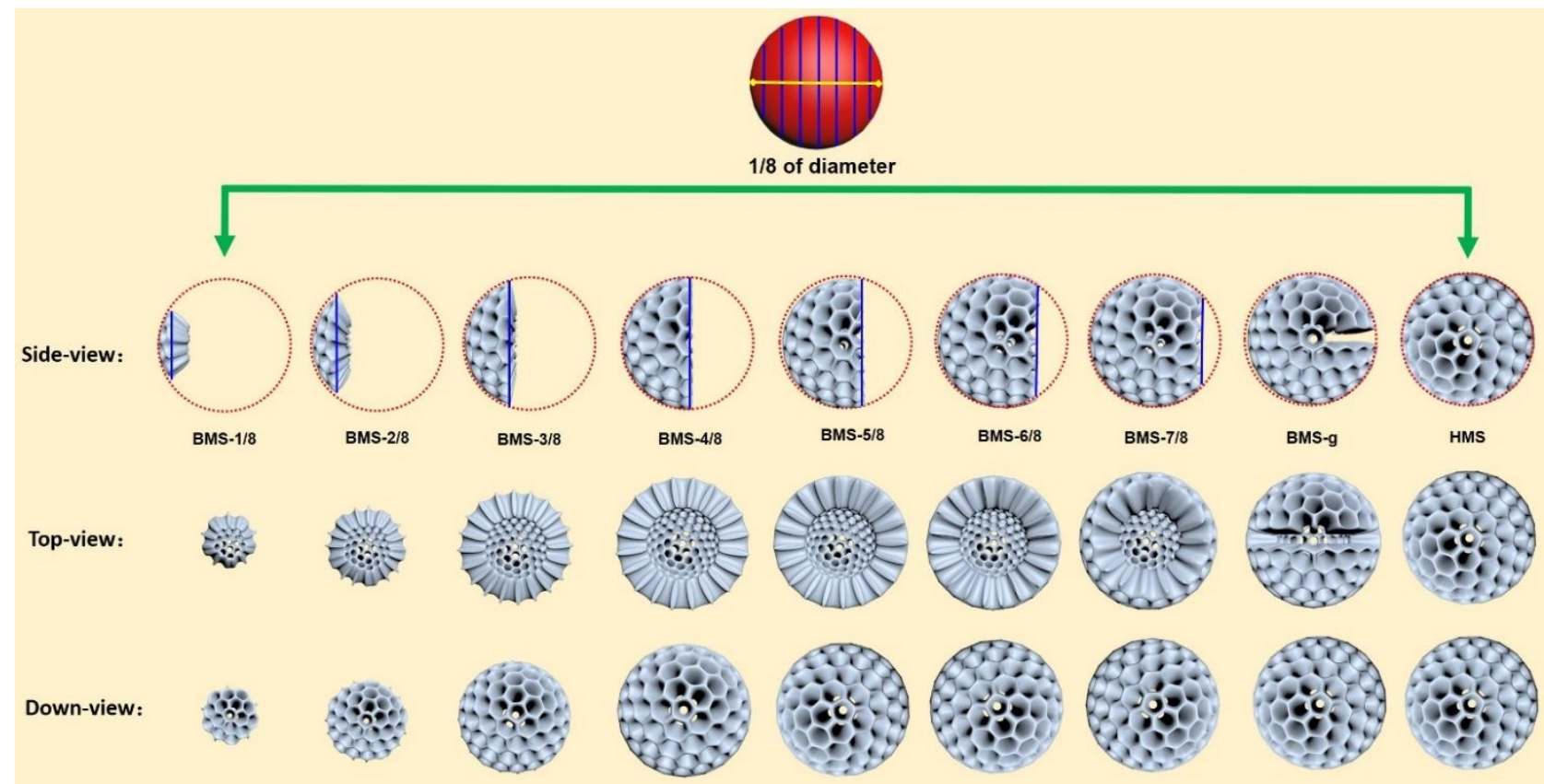

Figure S1 Schematic and corresponding definitions of the BMSs with different structural asymmetries observed in different views.

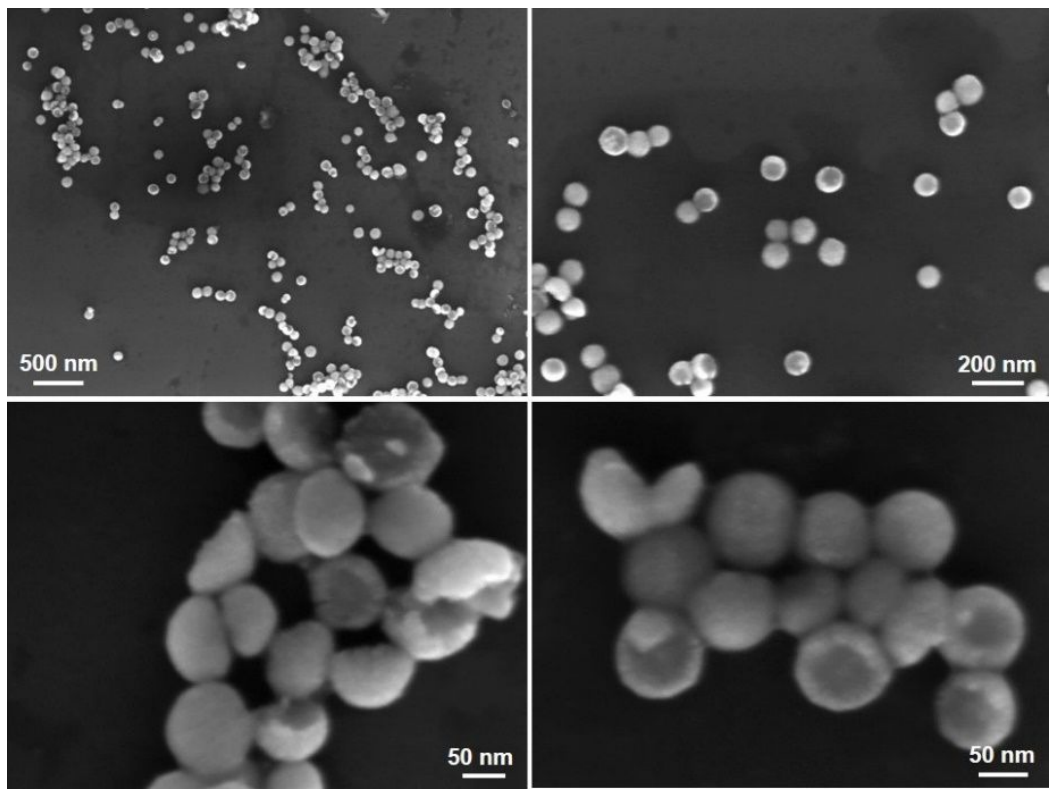

Figure S2. SEM images of trimetallic PdAgCu asymmetric BMS-4/8 with different magnifications. 


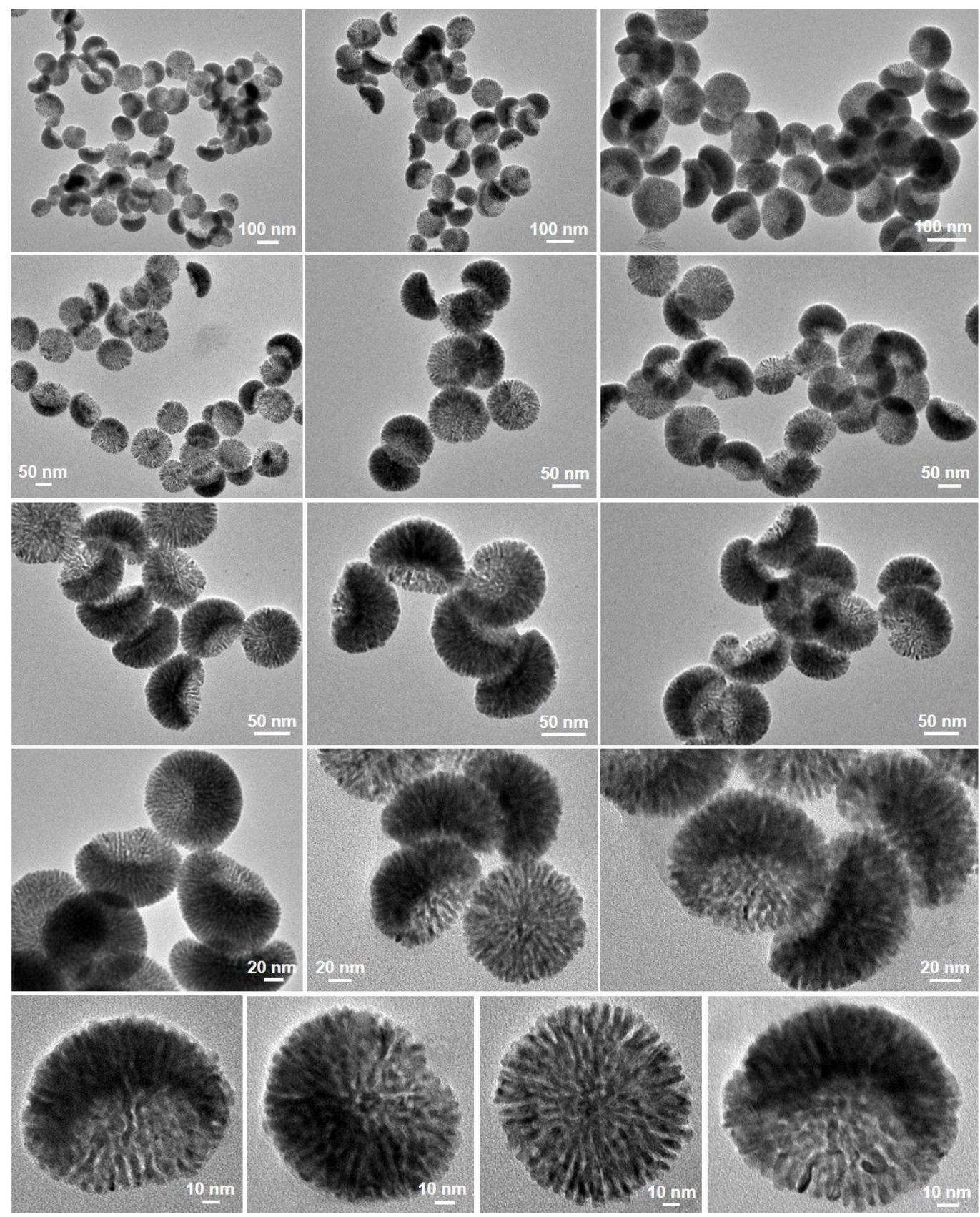

Figure S3 Additional TEM images of trimetallic PdAgCu asymmetric BMS-4/8, indicating asymmetric bowl-shaped hemispherical morphology with a high purity and uniformity. 


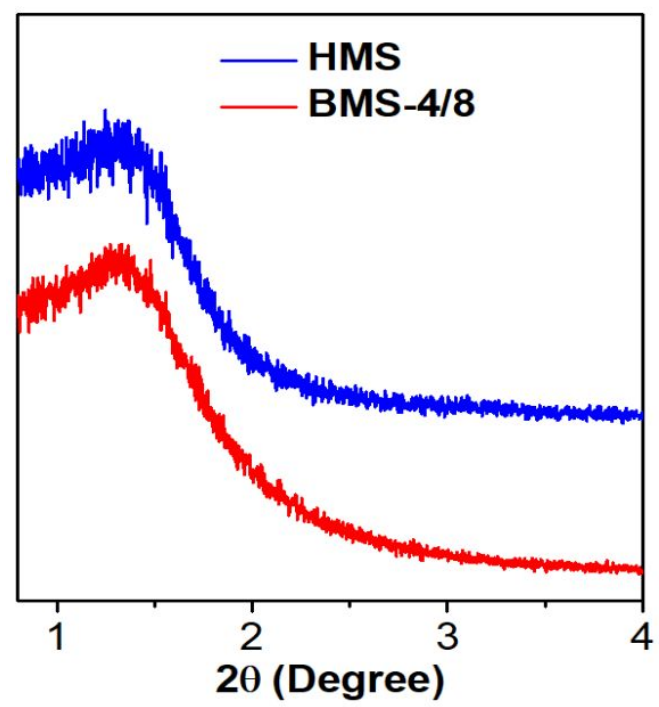

Figure S4 Small-angle XRD patterns of the PdAgCu BMS-4/8 and HMSs, indicating the average poreto-pore distance of $6.4 \mathrm{~nm}$.

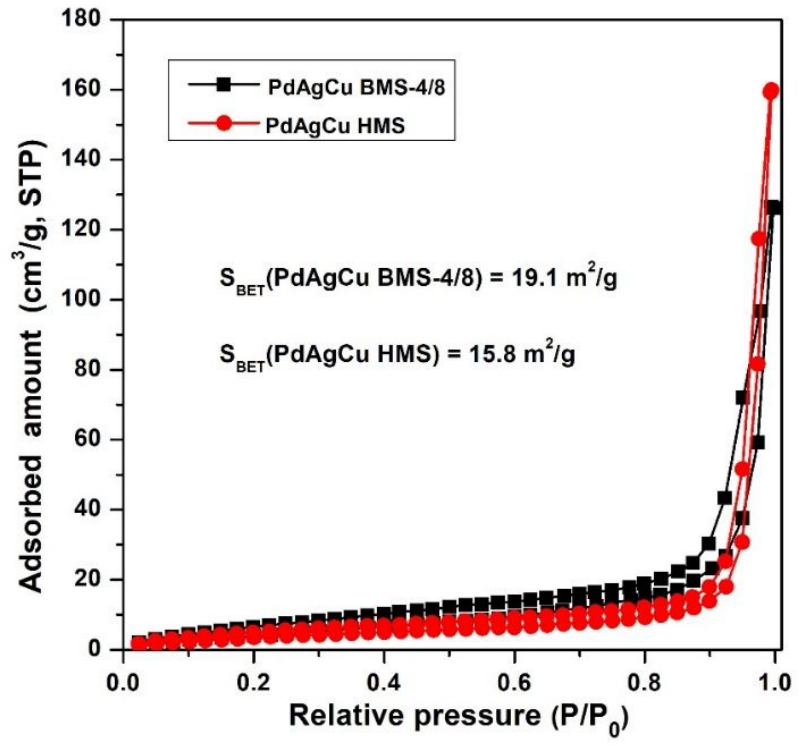

Figure $\mathbf{S 5} \mathrm{N}_{2}$ adsorption-desorption isotherms of PdAgCu BMS-4/8 and HMS.

Notes for Figure S5: The resulting PdAgCu BMS-4/8 possess a larger Brunauer-Emmett-Teller (BET) surface area due to the structural advantage. However, no clear uptakes are not observed in the middle relative pressure range, because the pore sizes are not strictly uniform, as observed by TEM. 


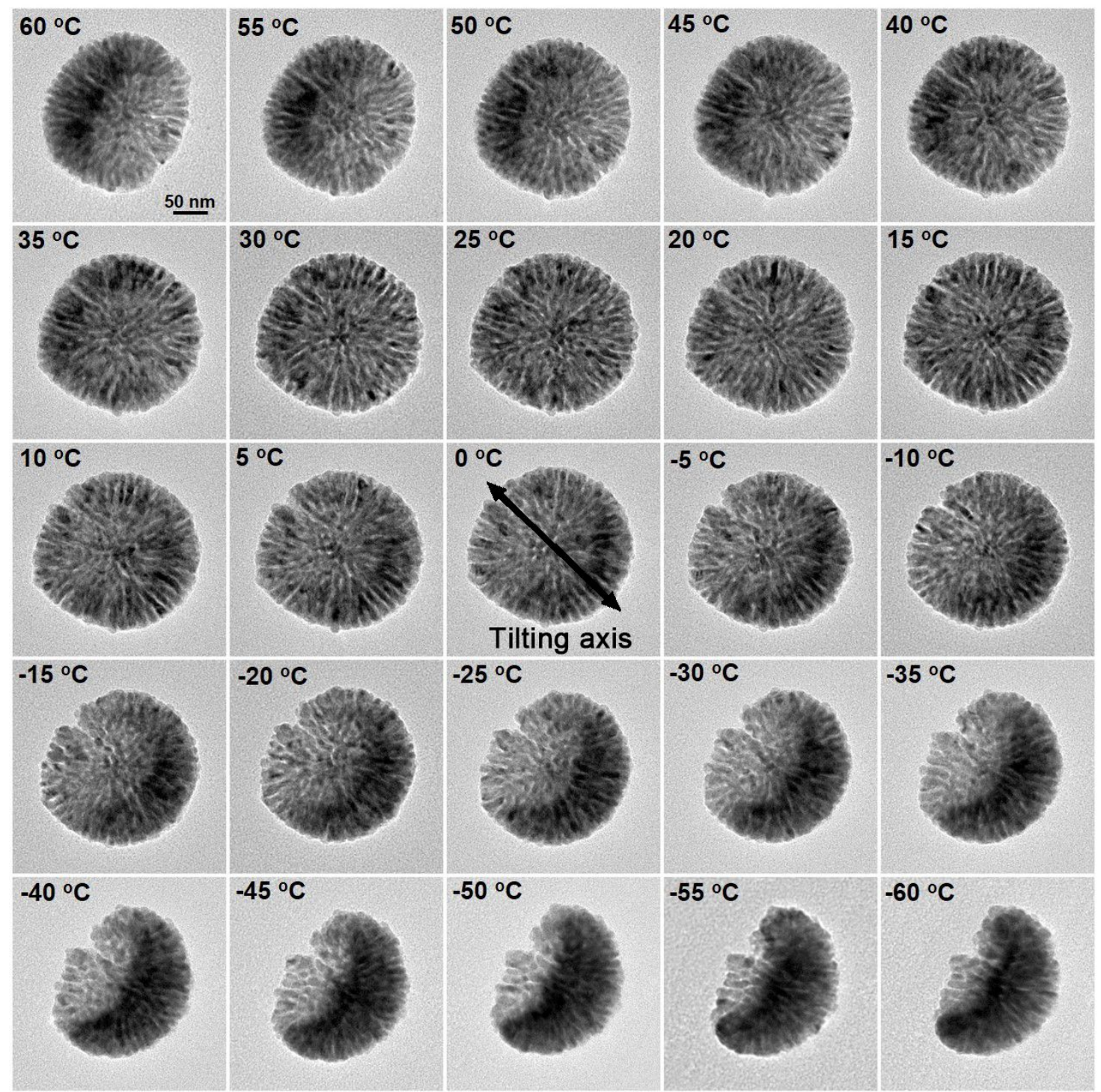

Figure S6 Tomographic TEM images of an individual BMS-4/8, indicating highly uniform asymmetric bowl-shaped nanospheres with cylindrically opened mesoporous nanostructures. 


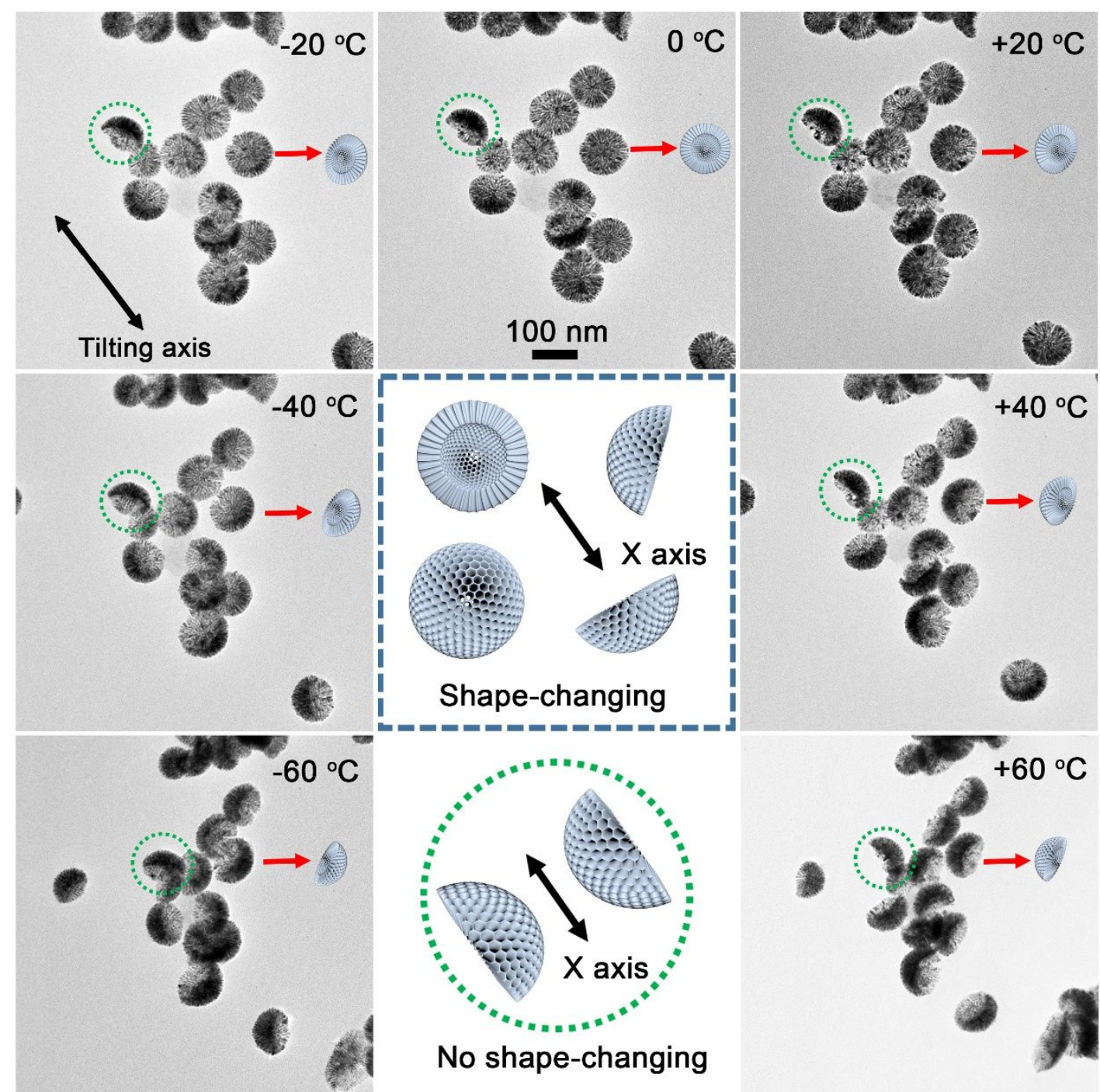

Figure S7. Tomographic TEM images of multiple BMS-4/8.

Notes for Figure S7: When tilting the BMSs-4/8 along the X axis of TEM observation platform, the shape of most of the BMSs (as schemed in the light blue square) will change along with the different observation angles. However, only the BMS-4/8, which stand vertically upon the TEM grid and with the special direction (parallel to the tilting direction of $\mathrm{X}$ axis) as labeled by the green circles, can keep their shapes. Tomographic TEM observations, therefore, definitely indicate that multiple BMS-4/8 possess bowlshaped hemispherical nanostructure with a pretty high purity and uniformity. 


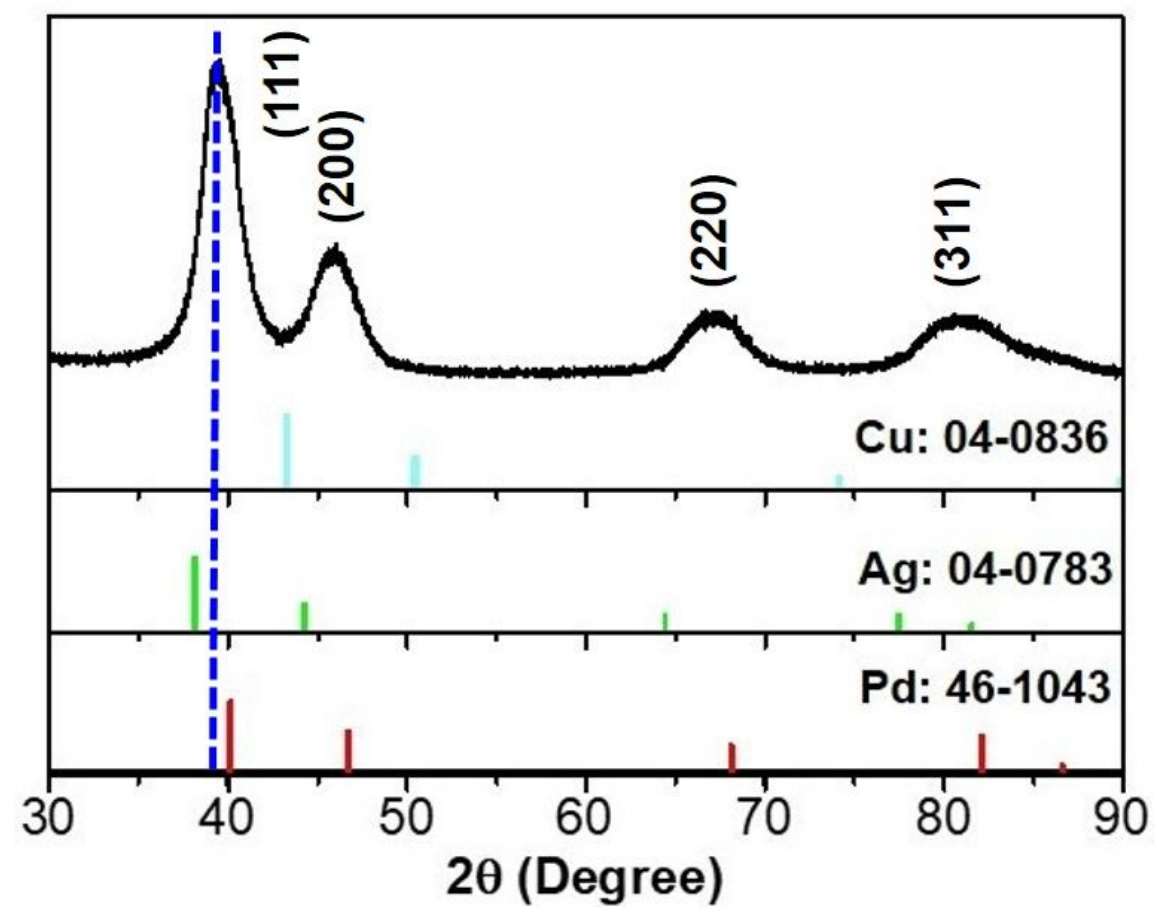

Figure S8 Wide-angle XRD pattern of trimetallic PdAgCu asymmetric BMS-4/8, suggesting an fcc crystalline structure with a $d$-spacing of $0.228 \mathrm{~nm}$.

Note for Figure S8: The typical peaks of multimetallic nanoalloys in wide-angle XRD patterns are strongly related to the elemental compositions and ratios, according to the Vegard's law (Phys. Rev. A, 1991, 43, 3161). From XRD patterns (with (111) peak of $39.45^{\circ}$ ), the d-spacing of (111) plane is calculated to be $0.228 \mathrm{~nm}$, which is located in between the values of pure Pd and $\mathrm{Ag}$. Considering that the content of $\mathrm{Ag}$ was much higher than $\mathrm{Cu}, \mathrm{PdAgCu}$ BMS-4/8 thus displays a slight shift of XRD peaks (and $d$-spacing) towards pure $\mathrm{Ag}$. This definitely indicates that trimetallic $\mathrm{PdAgCu}$ is compositionally alloyed rather than phase-separated. 

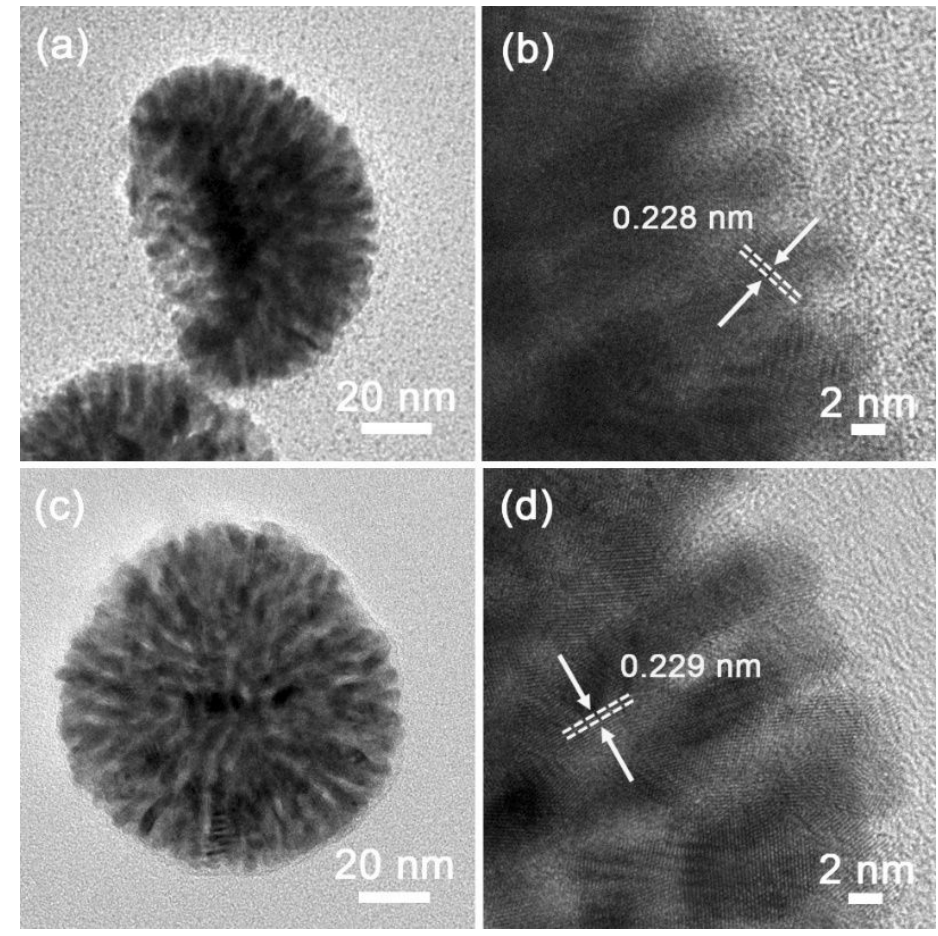

Figure S9 (a, c) High-magnification and (b, d) corresponding high-resolution TEM images of $\mathrm{PdAgCu}$ asymmetric BMS-4/8 with different observation angles.

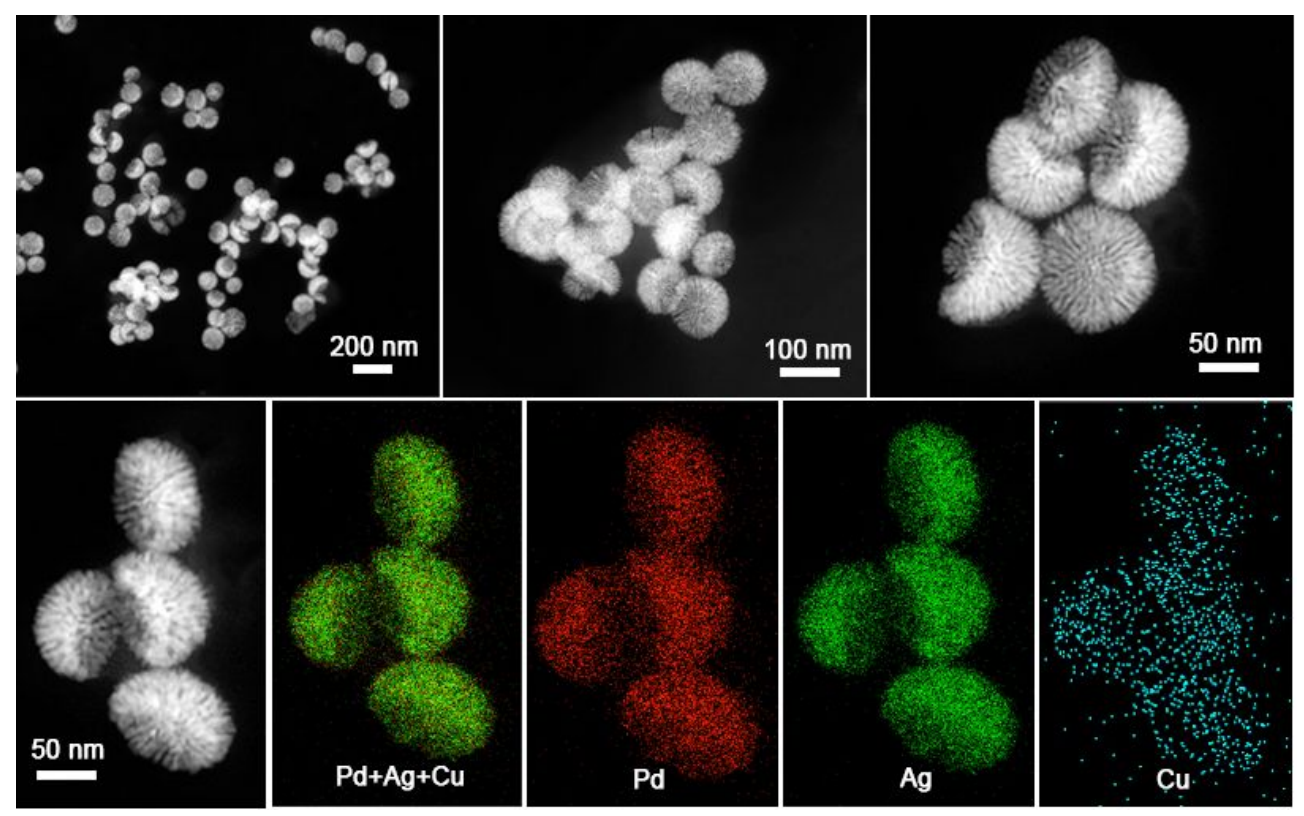

Figure S10 Low-magnification and high-magnification HAADF-STEM images, and STEM elemental mappings of $\mathrm{PdAgCu}$ asymmetric BMS-4/8. 


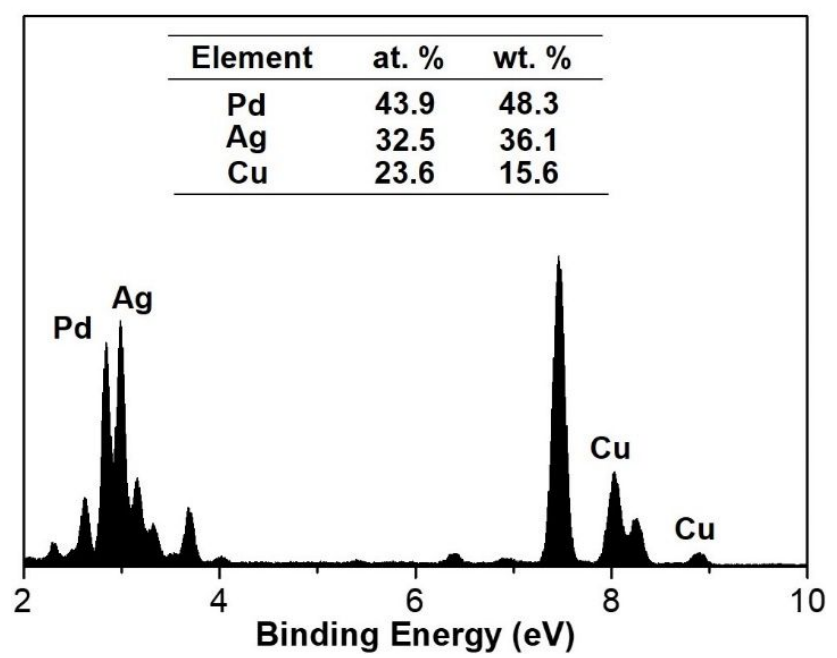

Figure S11 EDX spectrum of PdAgCu asymmetric BMS-4/8. The compositional ratio obtained from EDX is agreed well to the value from ICP-MS (46.7 : $37.4: 15.9$ by wt. \%).

Notes for Figure S11: Trimetallic PdAgCu asymmetric BHMs were prepared on a carbon coated nickel grid (300 mesh) for TEM EDX and mapping.
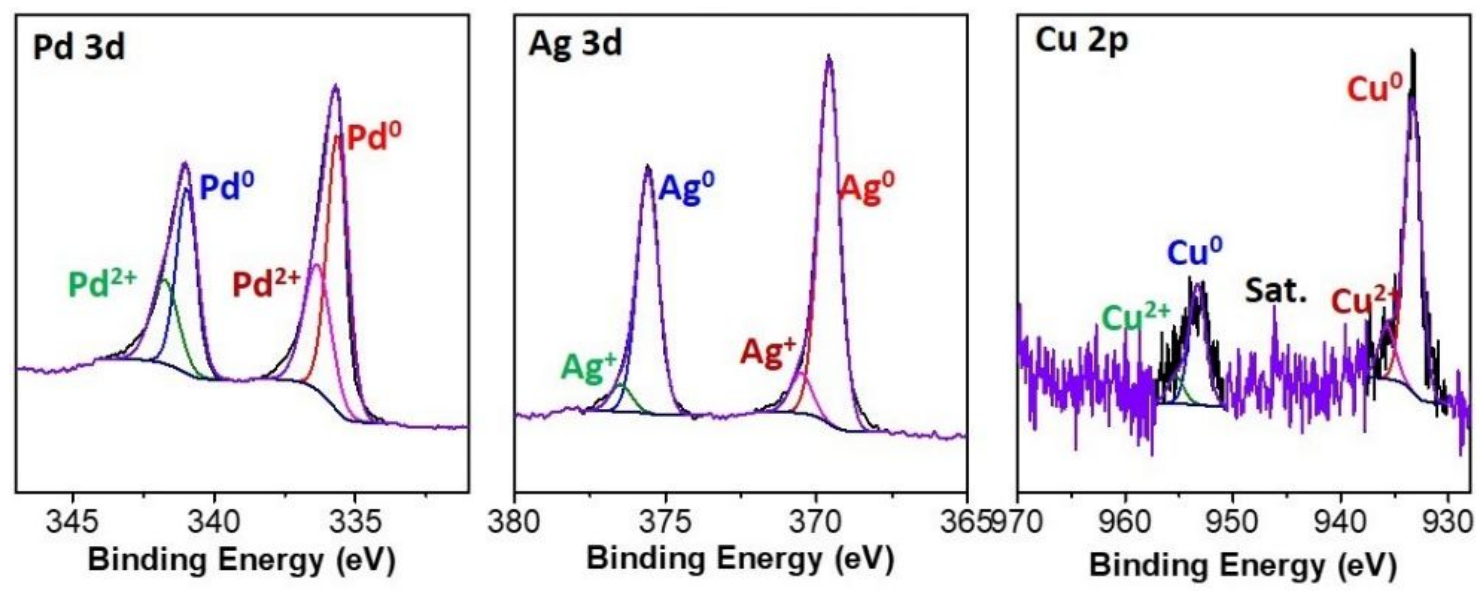

Figure S12 High-resolution XPS Pd 3d, Ag 3d and Cu 2p spectra of PdAgCu BMS-4/8.

Notes for Figure S12: The positive shifts in binding energy and small amount of oxidized species $(<10 \%)$ of $\mathrm{Pd}, \mathrm{Ag}$ and $\mathrm{Cu}$ are seen, compared to its pure metal counterparts. The results display the upshift of core levels in the Fermi levels, further indicating the formation of alloyed $\mathrm{PdAgCu}$. 


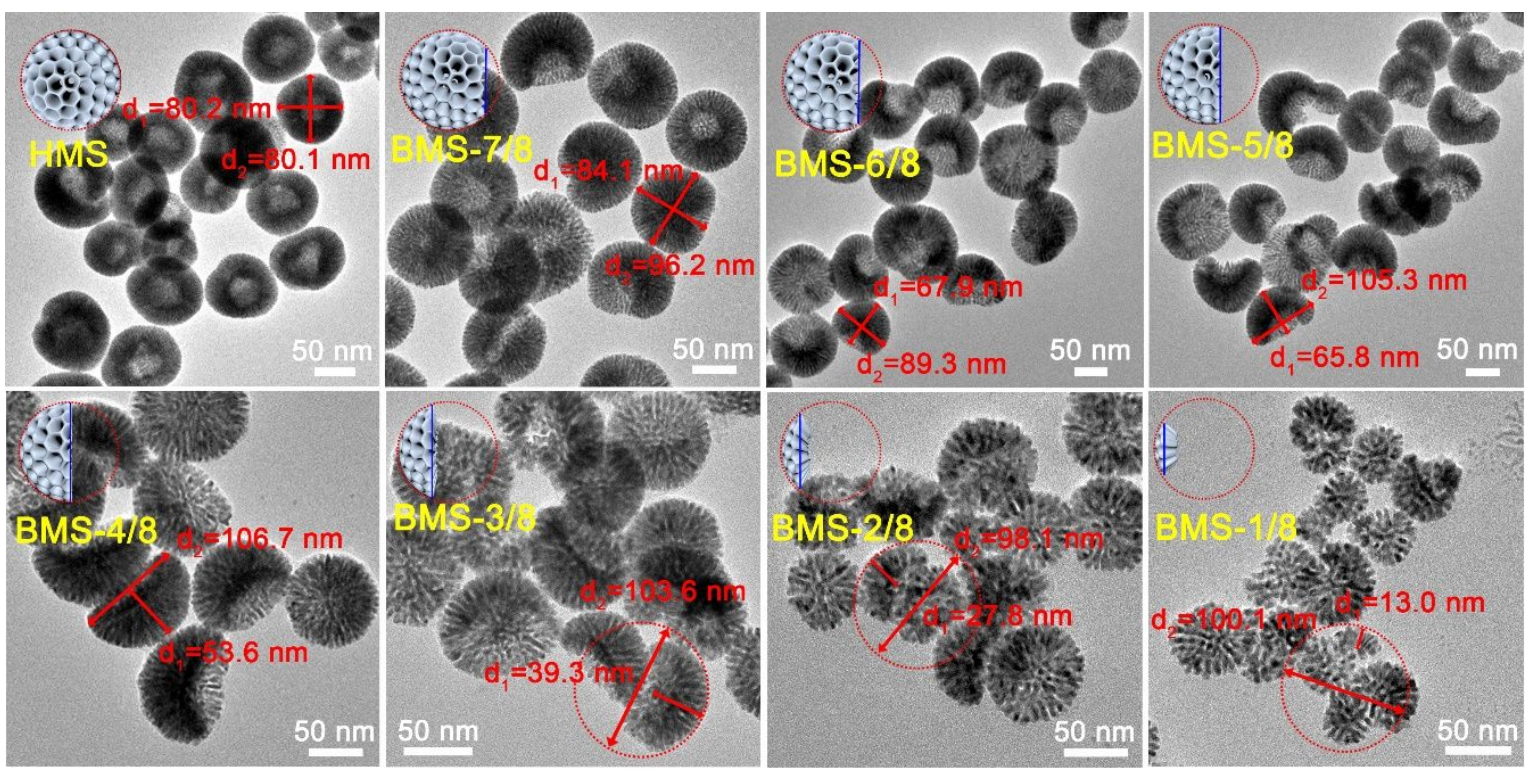

Figure S13 The diameters of PdAgCu BMSs with different asymmetries on vertical configuration.

Notes for Figure S13: The final $d_{1} / d_{2}$ values are approximatively equal to the standard values of the BMSs schemed in Figure S1, that is, HMS (1), BMSs-7/8 (0.875), BMSs-6/8 (0.75), BMSs-5/8 (0.625), BMSs-4/8 (0.5), BMSs-3/8 (0.375), BMSs-2/8 (0.25), and BMSs-1/8 (0.125), respectively. 

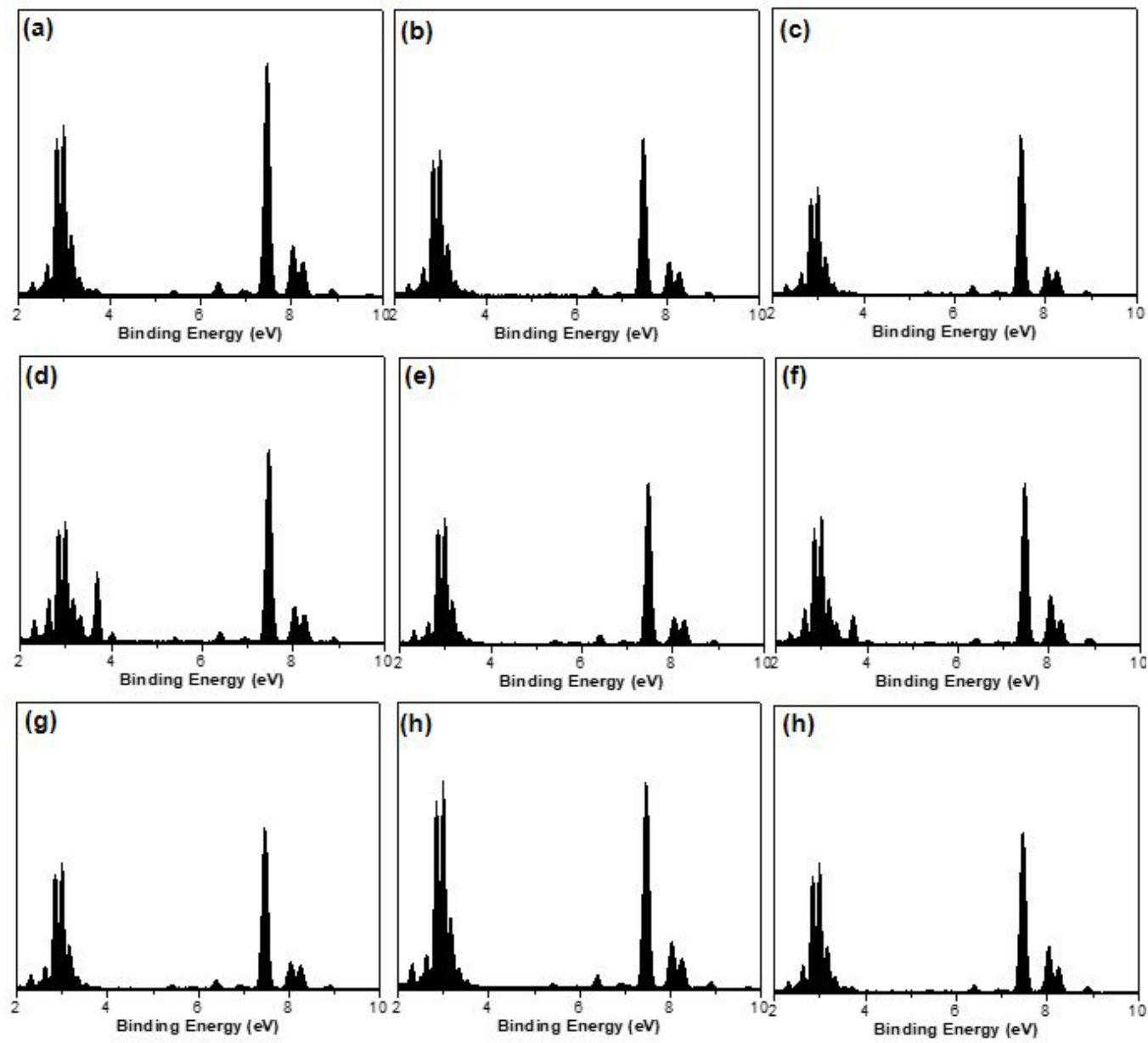

Figure S14 EDX spectra of the PdAgCu nanostructures synthesized under different conditions: (a-g) DODAC concentrations, two typical $\mathrm{pH}$ values of $(\mathrm{g}) 6.07$ and $(\mathrm{h}) 8.62$, and $(\mathrm{h})$ a typical reaction temperature of $50^{\circ} \mathrm{C}$.

Notes for Figure S14: All the PdAgCu BMSs/HMSs possess the similar compositional ratios, that almost match to their feed ratios, indicating the compositional ratio may be not the key in engineering the asymmetric nanostructures. 

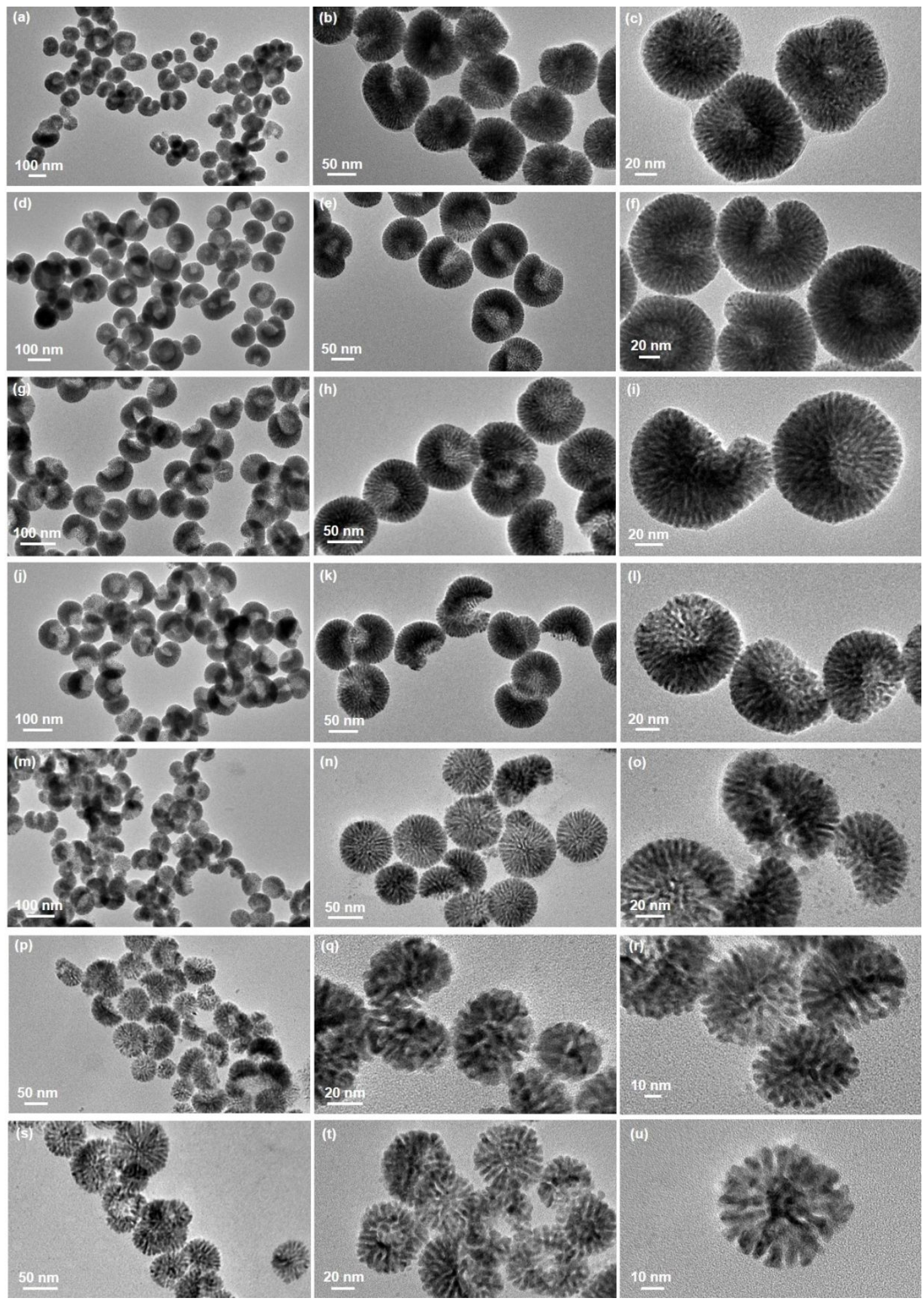

Figure S15 TEM images of PdAgCu BMSs with different structural asymmetries: (a-c) BMS-g, (d-f) BMS-7/8, (g-i) BMS-6/8, (j-1) BMS-5/8, (m-o) BMS-3/8, (p-r) BMS-2/8 and (s-u) BMS-1/8. 

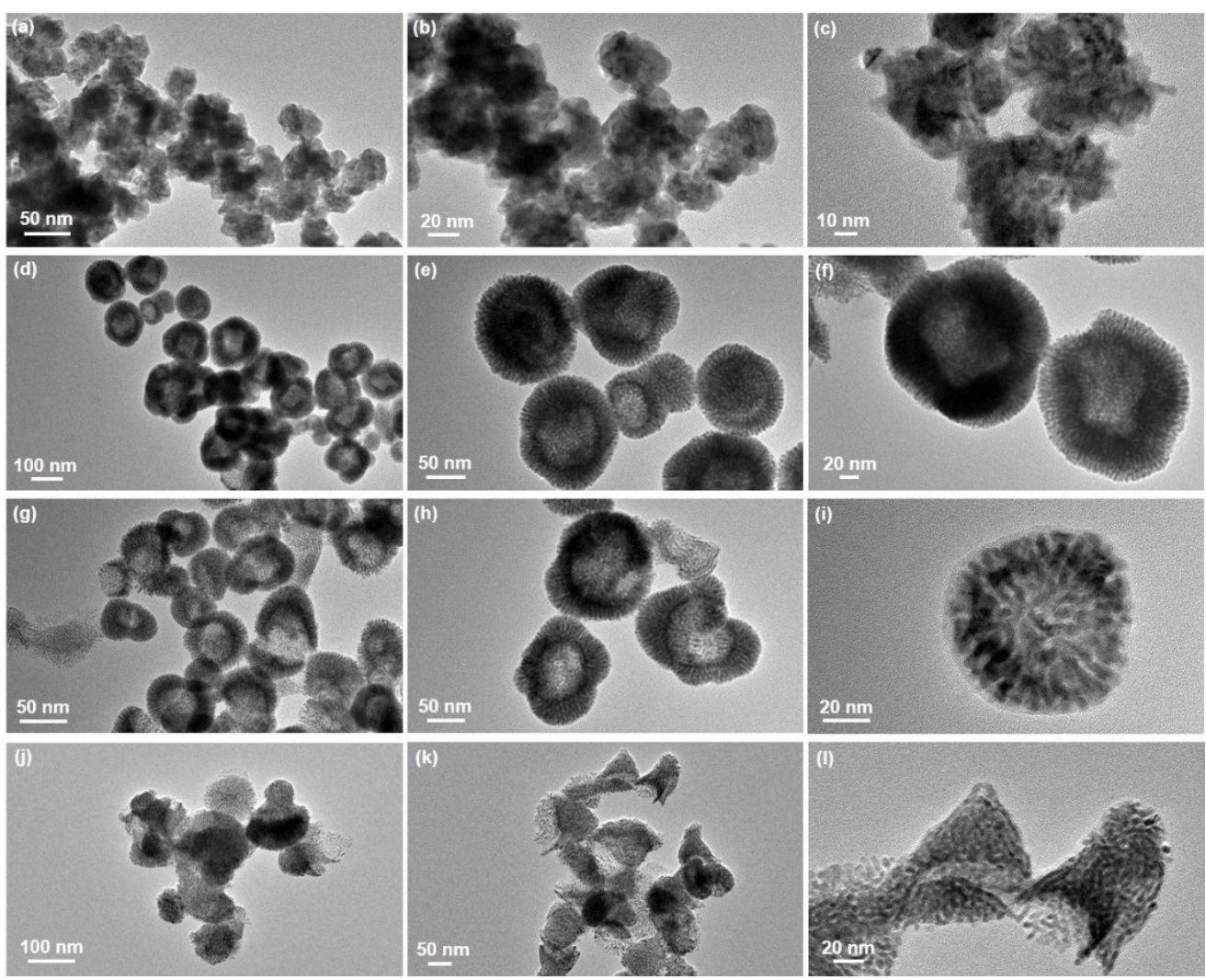

Figure S16 TEM images of PdAgCu nanostructures synthesized with different DODAC concentration of (a-c) $0 \mathrm{mg} \mathrm{mL}^{-1}$, (d-f) $0.05 \mathrm{mg} \mathrm{mL}^{-1}$, (g-i) $0.1 \mathrm{mg} \mathrm{mL}^{-1}$, and (j-1) $4 \mathrm{mg} \mathrm{mL}^{-1}$. 

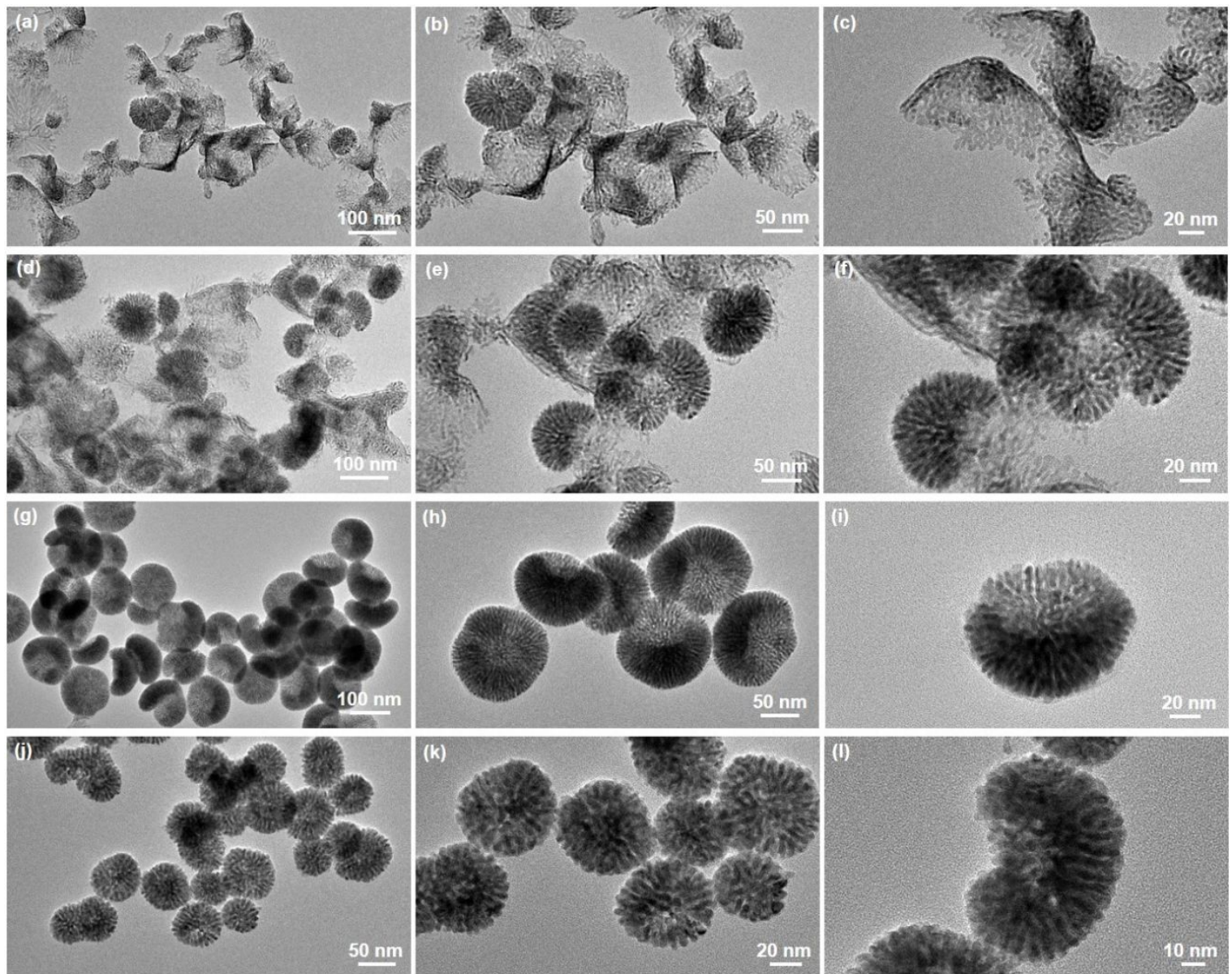

Figure S17 TEM images of $\mathrm{PdAgCu}$ nanostructures synthesized with different metal precursor concentration of (a-c) $0.002 \mathrm{M}$, (d-f) $0.005 \mathrm{M}$, (g-i) $0.01 \mathrm{M}$, and (j-1) $0.02 \mathrm{M}$. 

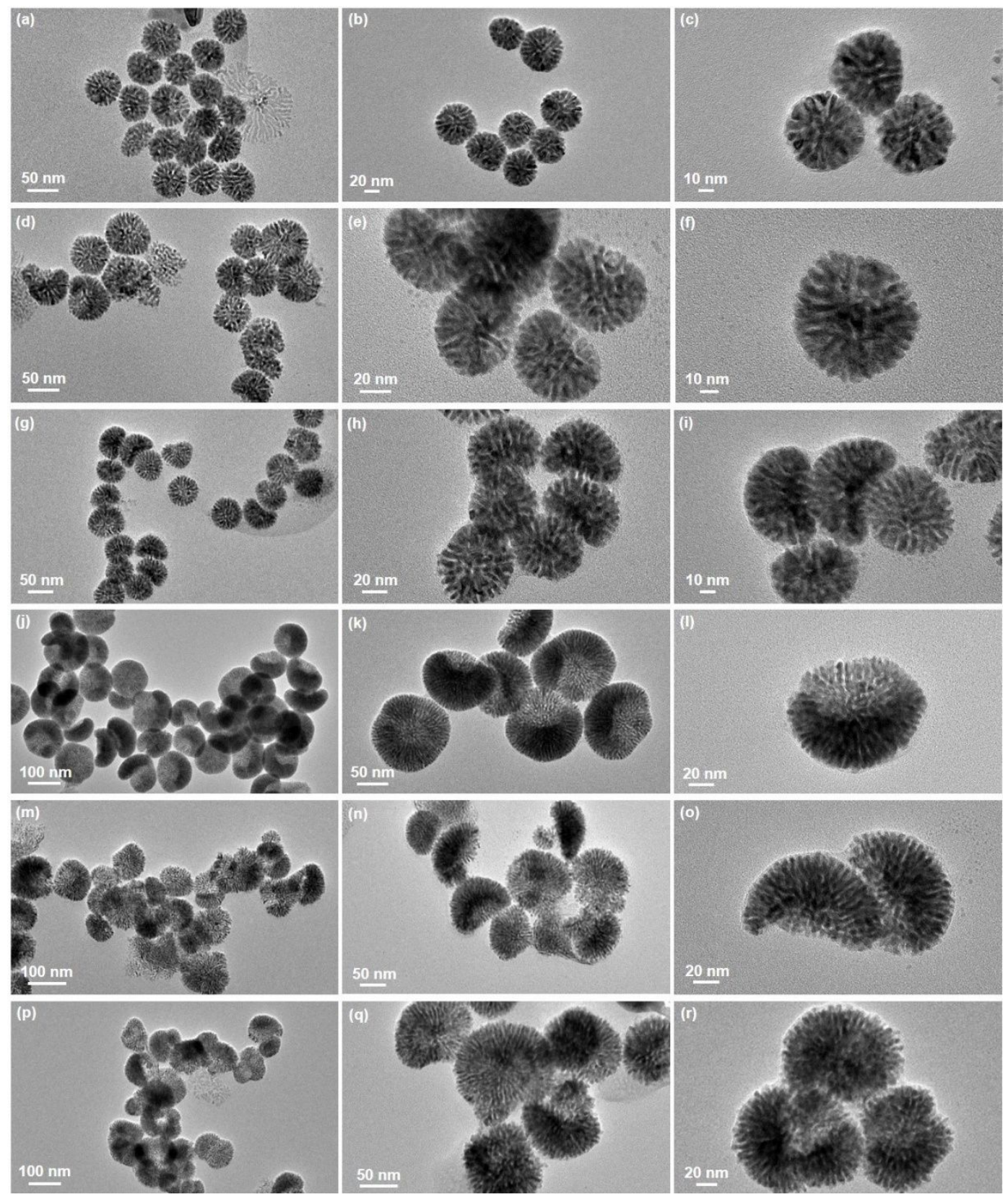

Figure S18 TEM images of PdAgCu nanostructures synthesized with different pHs of (a-c) 5.86, (d-f) 6.07, (g-i) 6.63, (j-1) 7.11, (m-o) 7.56, and (p-r) 8.62. 

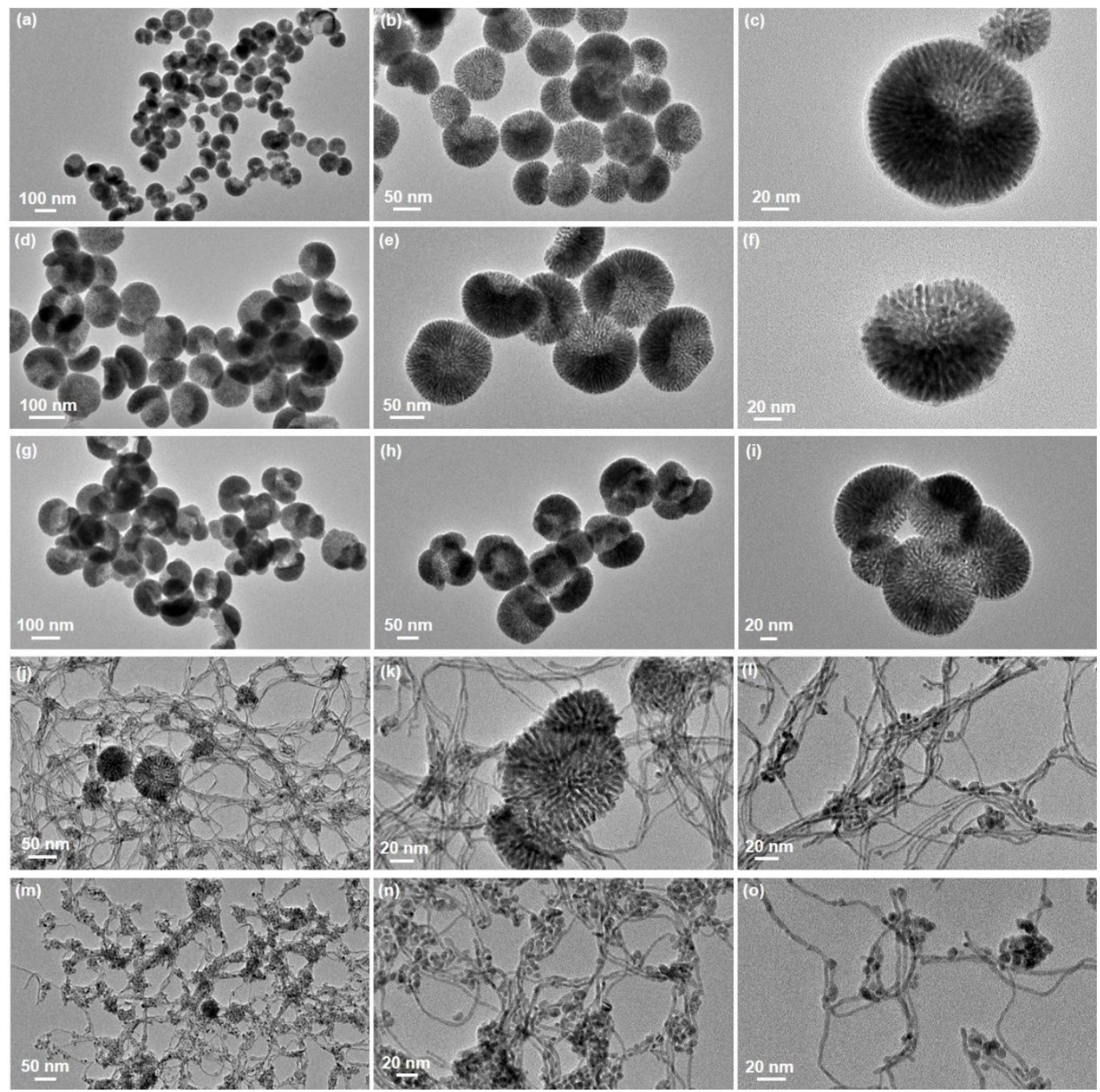

Figure S19 TEM images of PdAgCu nanostructures synthesized with different reaction temperature of (a-c) $0{ }^{\circ} \mathrm{C}$, (d-f) $25^{\circ} \mathrm{C}$, (g-i) $50{ }^{\circ} \mathrm{C},(\mathrm{j}-1) 75^{\circ} \mathrm{C}$, and (m-o) $95^{\circ} \mathrm{C}$. 

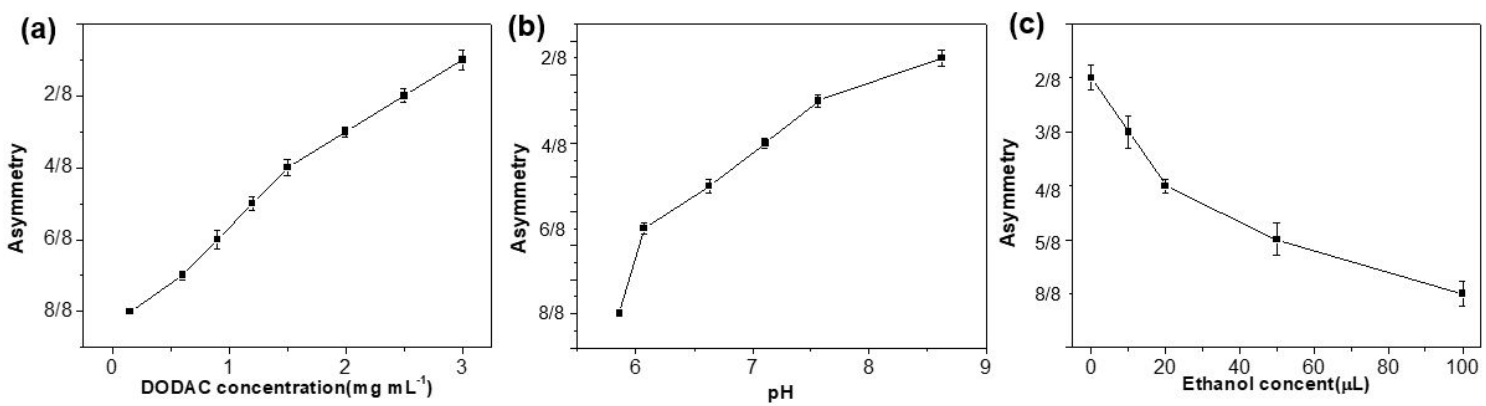

Figure S20 Asymmetry control diagrams. Controlling the structural asymmetries of the PdAgCu BMSs by (a) DODAC concentration, (b) $\mathrm{pH}$ of the reaction solution, and (c) the content of co-solvent of ethanol.

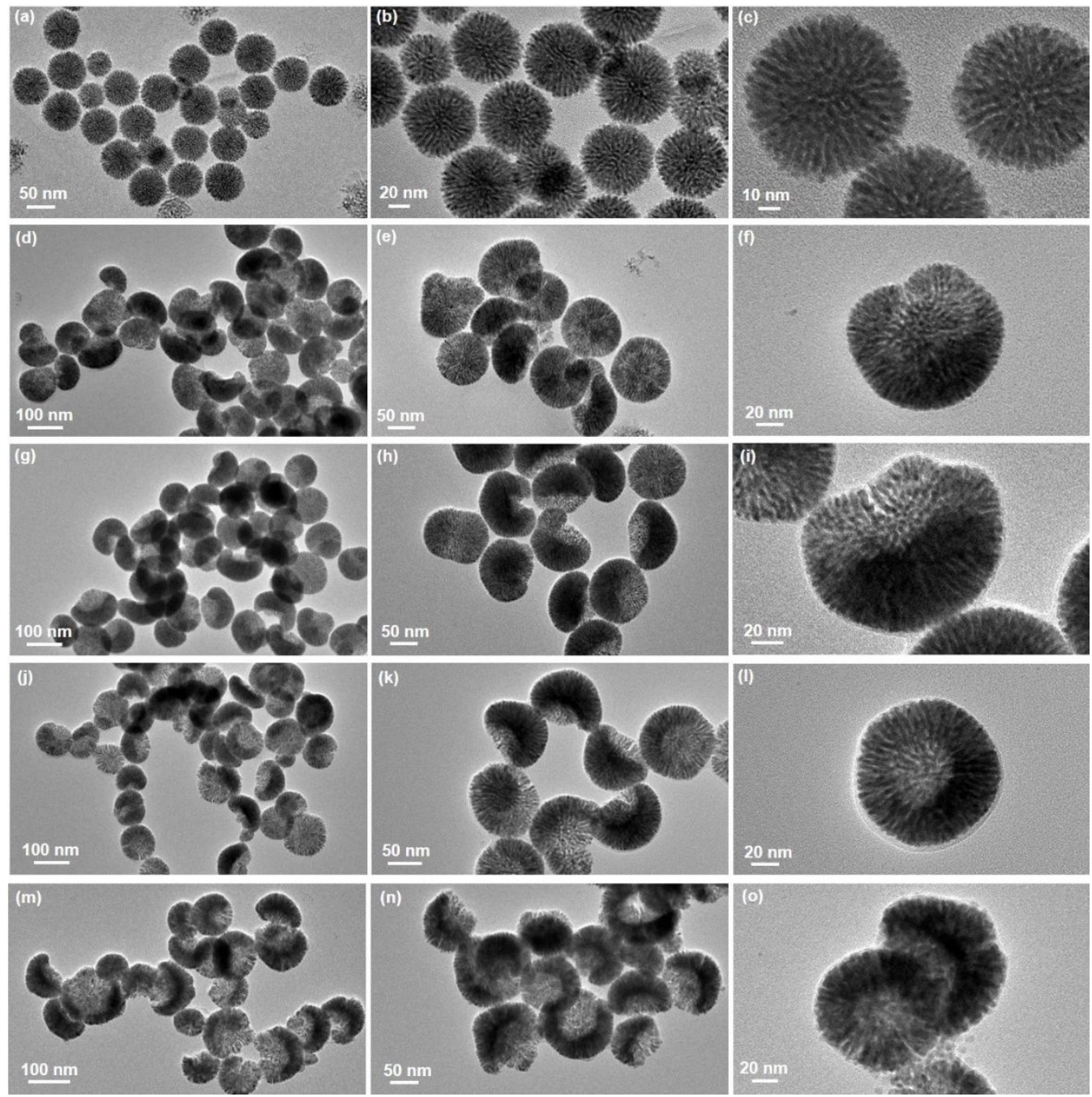

Figure S21 TEM images of the PdAgCu nanostructures synthesized with different Ag content of (a-c) 0 , (d-f) 21.4 wt. \%, (g-i) 36.1 wt. \%, (j-1) 51.2 wt. \%, and (m-o) 64.7 wt. \%. 


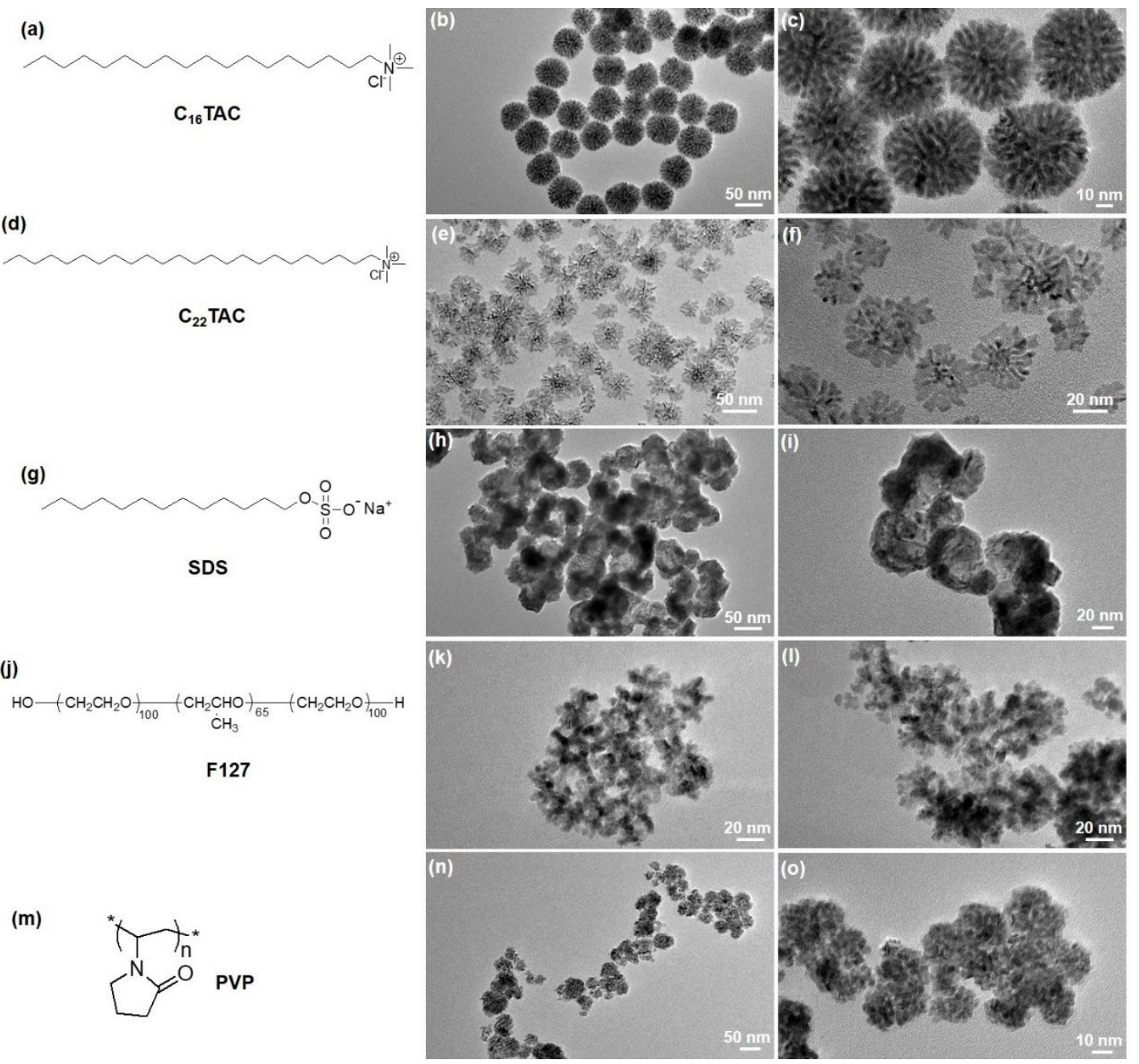

Figure S22 TEM images of $\mathrm{PdAgCu}$ nanostructures synthesized with different surfactant of (a-c) $\mathrm{C}_{16} \mathrm{TAC}$, (d-f) $\mathrm{C}_{22} \mathrm{TAC}$, (g-i) SDS, (j-1) F127, and (m-o) PVP. 

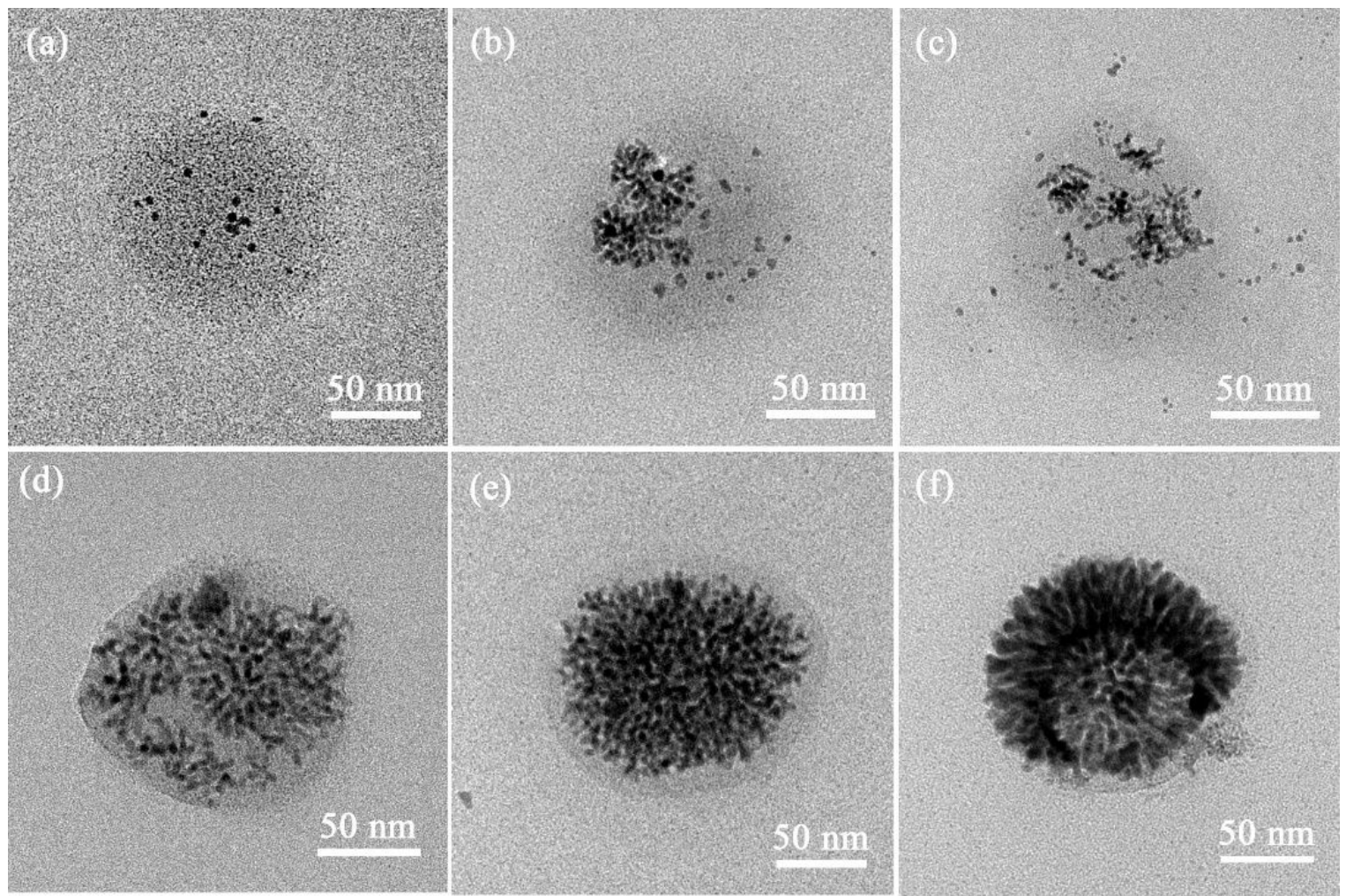

Figure S23 Typical TEM images of the PdAgCu BMS-4/8 obtained at different crystalline periods, indicating the island growth mechanism. The time interval in a-f is $5 \mathrm{~s}, 10 \mathrm{~s}, 20 \mathrm{~s}, 30 \mathrm{~s}, 45 \mathrm{~s}$, and $60 \mathrm{~s}$, respectively. 

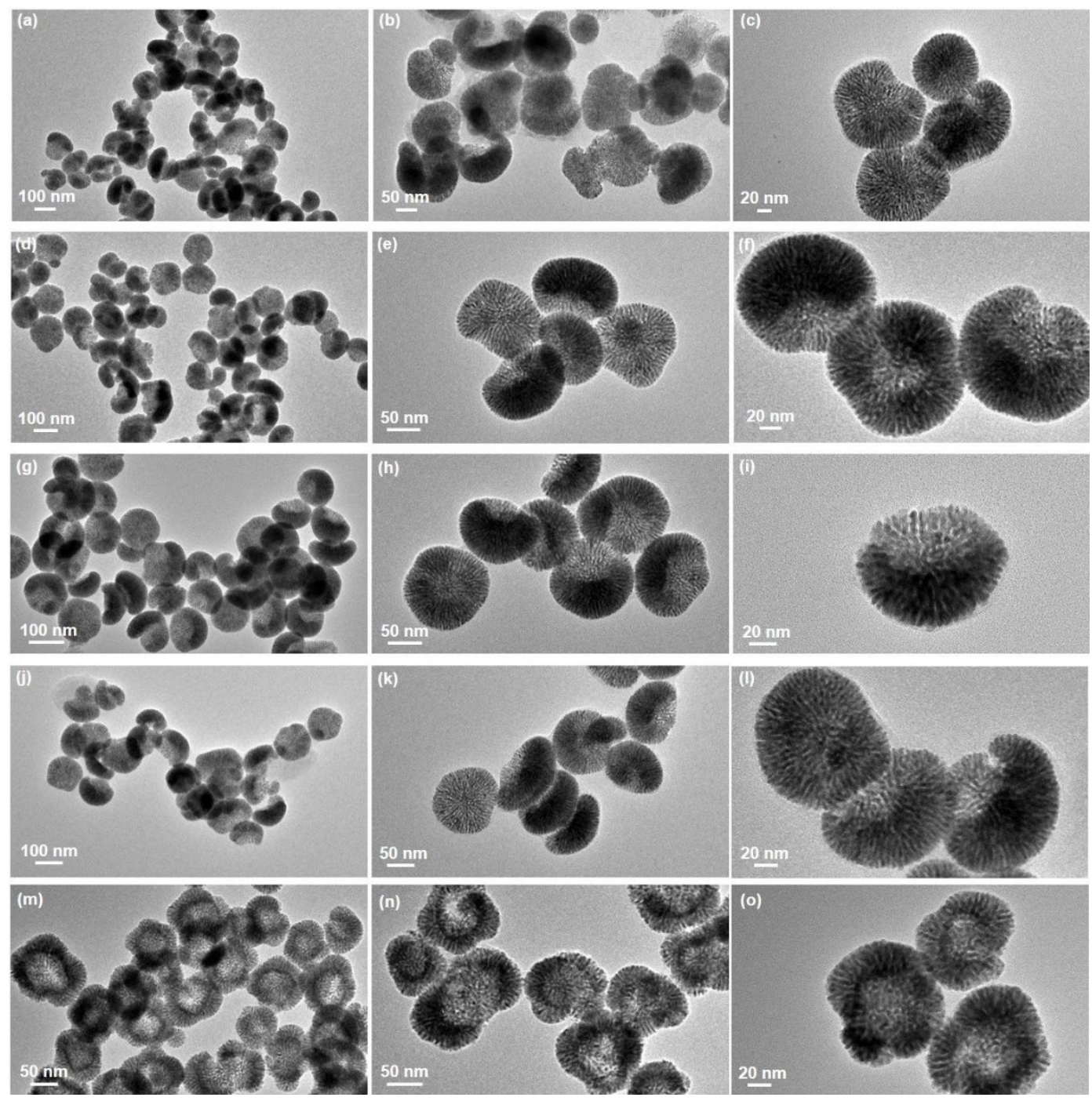

Figure S24 TEM images of the PdAgCu nanostructures synthesized with different ethanol content of (ac) 0 , (d-f) $10 \mu \mathrm{L},(\mathrm{g}-\mathrm{i}) 20 \mu \mathrm{L},(\mathrm{j}-1) 50 \mu \mathrm{L}$, and (m-o) $100 \mu \mathrm{L}$. 


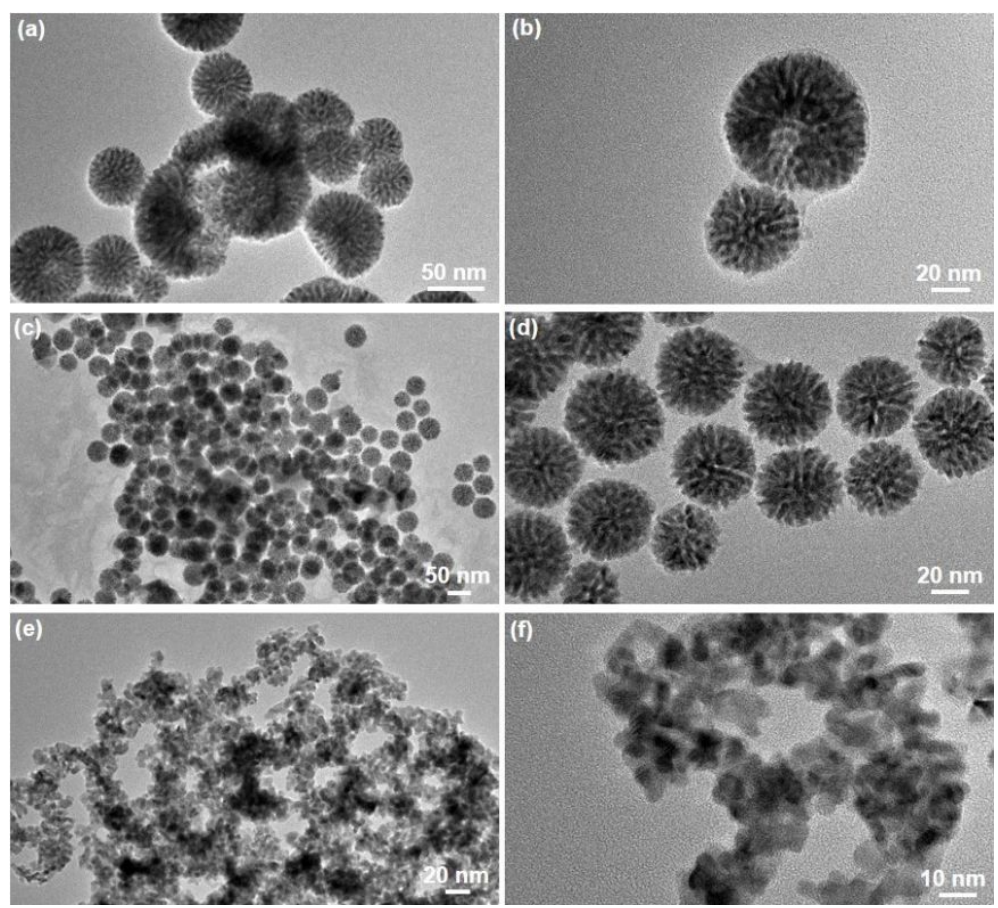

Figure S25 TEM images of the PdAgCu nanostructures synthesized with different ethanol content of (a, b) $0.5 \mathrm{~mL}$, (c, d) $2.0 \mathrm{~mL}$, and (e, f) $4.0 \mathrm{~mL}$ (total $10 \mathrm{~mL}$ of $\mathrm{H}_{2} \mathrm{O} /$ ethanol). 


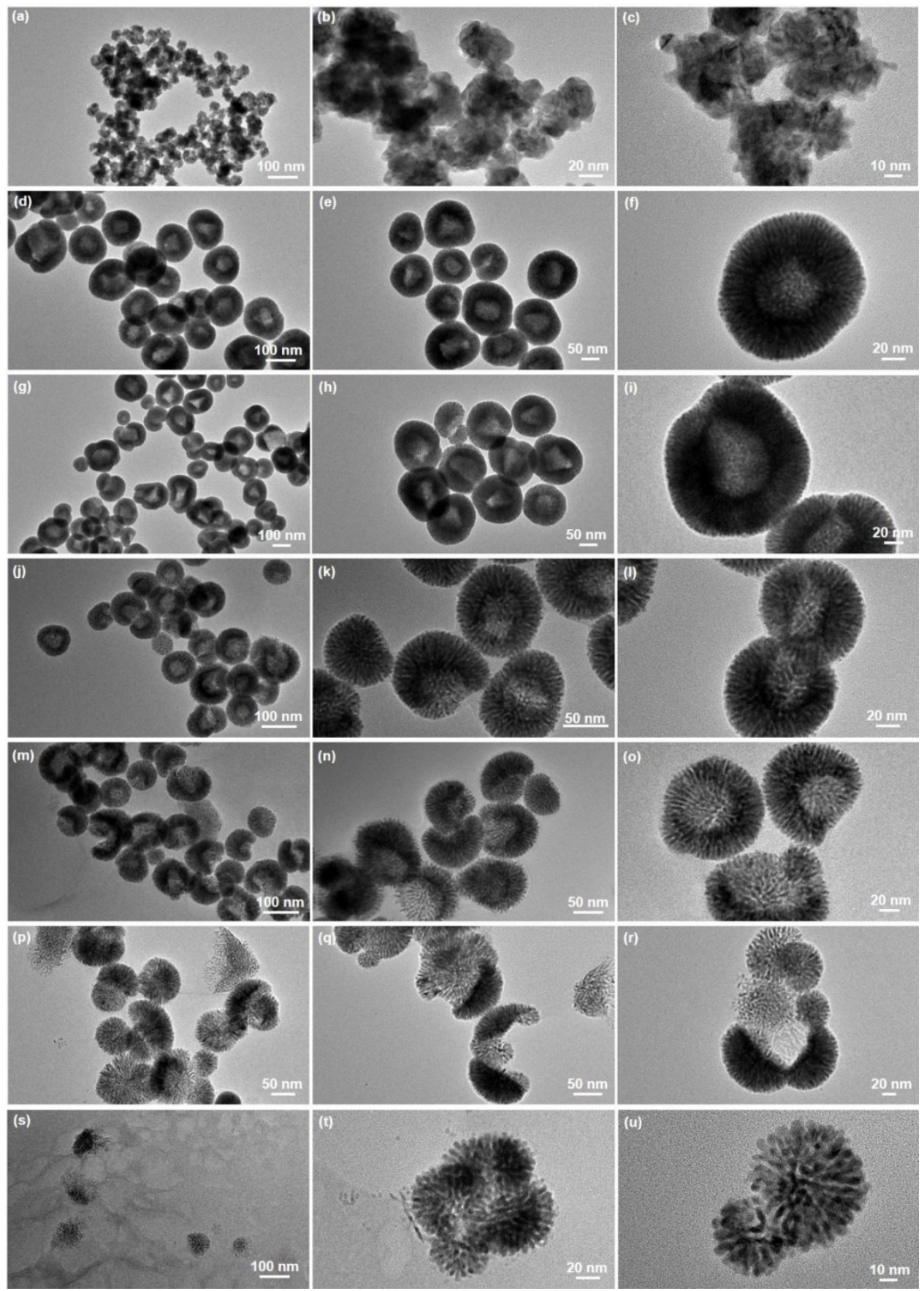

Figure S26 TEM images of the $\mathrm{PdAgCu}$ nanostructures synthesized in the absence of ethanol with different DODAC concentration of (a-c) 0, (d-f) $0.3 \mathrm{mg} \mathrm{mL}^{-1},(\mathrm{~g}-\mathrm{i}) 0.6 \mathrm{mg} \mathrm{mL}^{-1},(\mathrm{j}-1) 0.9 \mathrm{mg} \mathrm{mL}^{-1},(\mathrm{~m}-\mathrm{o})$ $1.5 \mathrm{mg} \mathrm{mL}^{-1}$, (p-r) $2.0 \mathrm{mg} \mathrm{mL}^{-1}$ and (s-u) $3.0 \mathrm{mg} \mathrm{mL}^{-1}$. These results imply that ethanol is a necessary component in the co-solvent to ensure that the BMSs are asymmetric and uniform. 


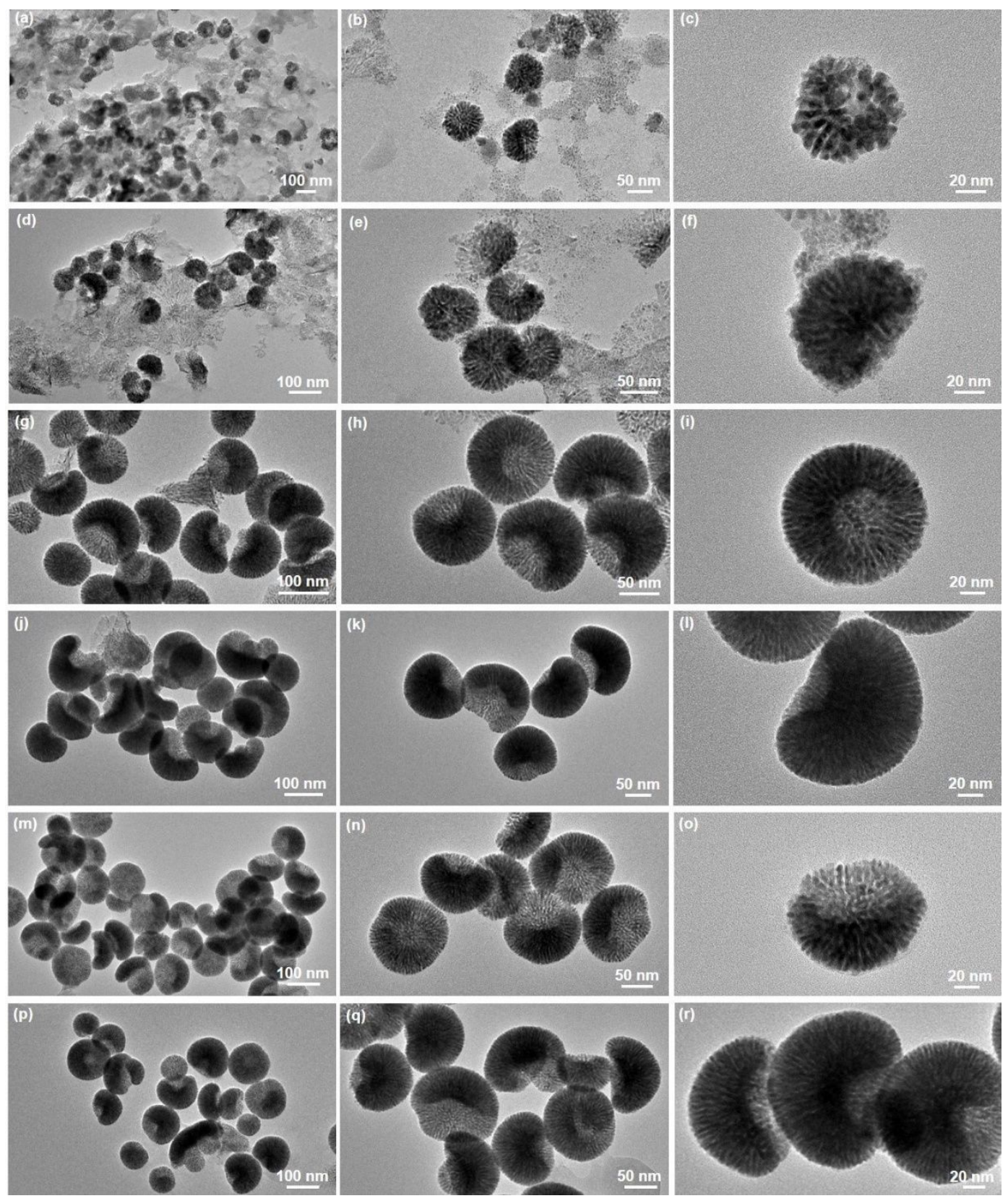

Figure S27 TEM images of the PdAgCu nanostructures synthesized with different AA amounts. The molar ratio of AA/metal precursors is (a-c) 1, (d-f) 2, (g-i) 5, (j-1) 10, (m-o) 20, and (p-r) 30, respectively. 

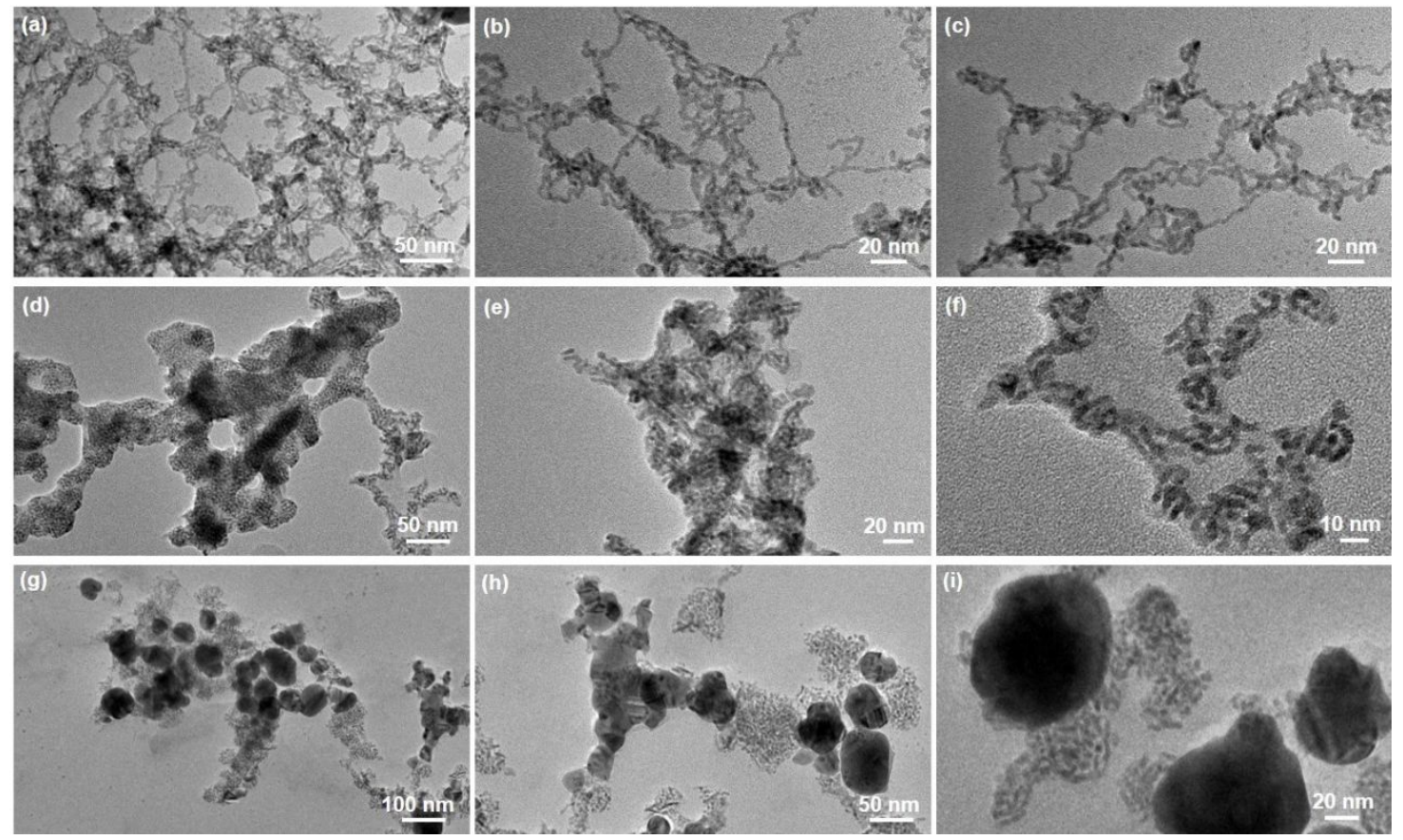

Figure S28 TEM images of the PdAgCu nanostructures synthesized with different reducing agents: (a-c) $\mathrm{N}_{2} \mathrm{H}_{4}$, (d-f) $\mathrm{NaH}_{2} \mathrm{PO}_{2}$ and (g-i) $\mathrm{NaBH}_{4}$.

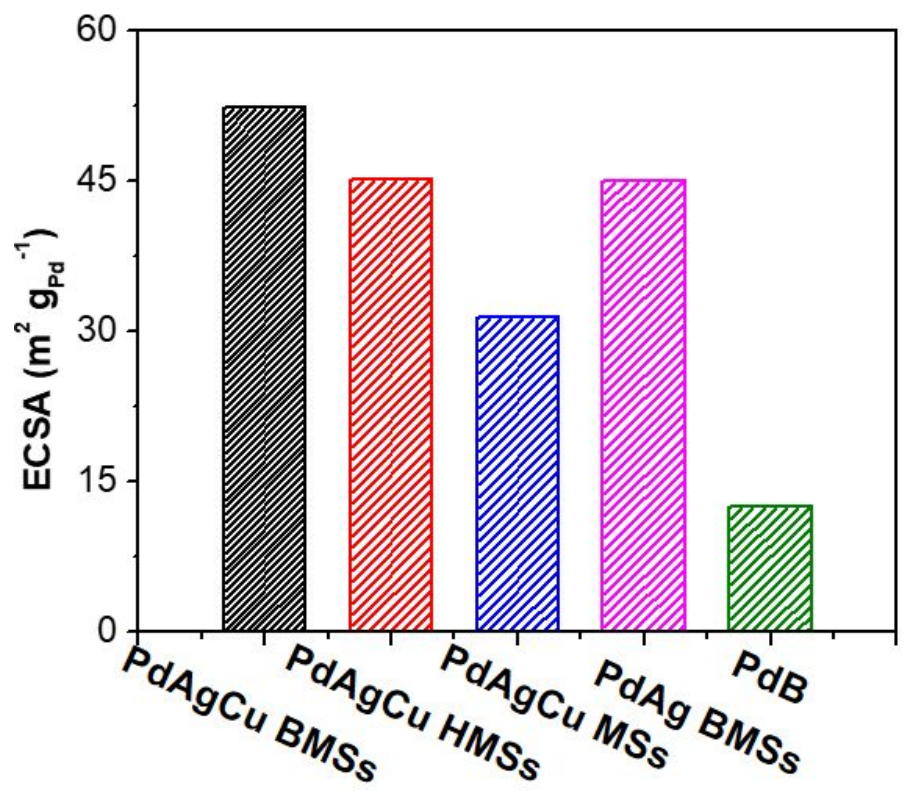

Figure S29 Summarized ECSAs of trimetallic PdAgCu BMSs, HMSs and MSs, bimetallic PdAg BMSs, commercial PdB obtained in $1.0 \mathrm{M} \mathrm{N}_{2}$-saturated $\mathrm{KOH}$ with a scan rate of $50 \mathrm{mV} \mathrm{s}^{-1}$. 


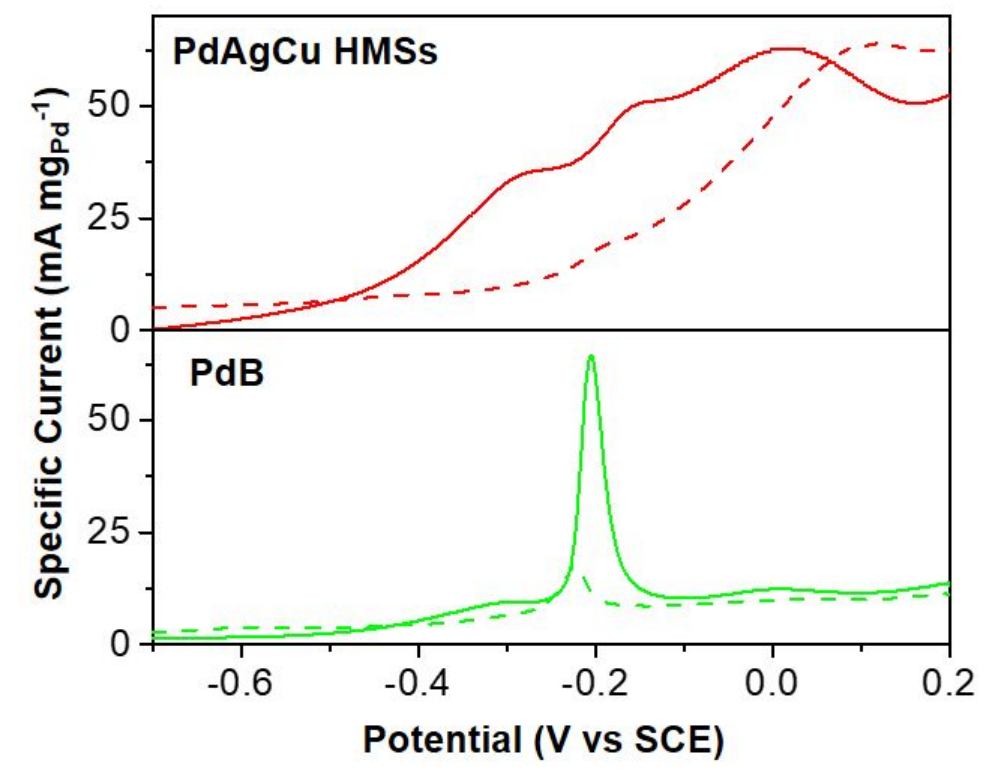

Figure S30 CO stripping curves of (a) PdAgCu HMSs and (b) commercial PdB.

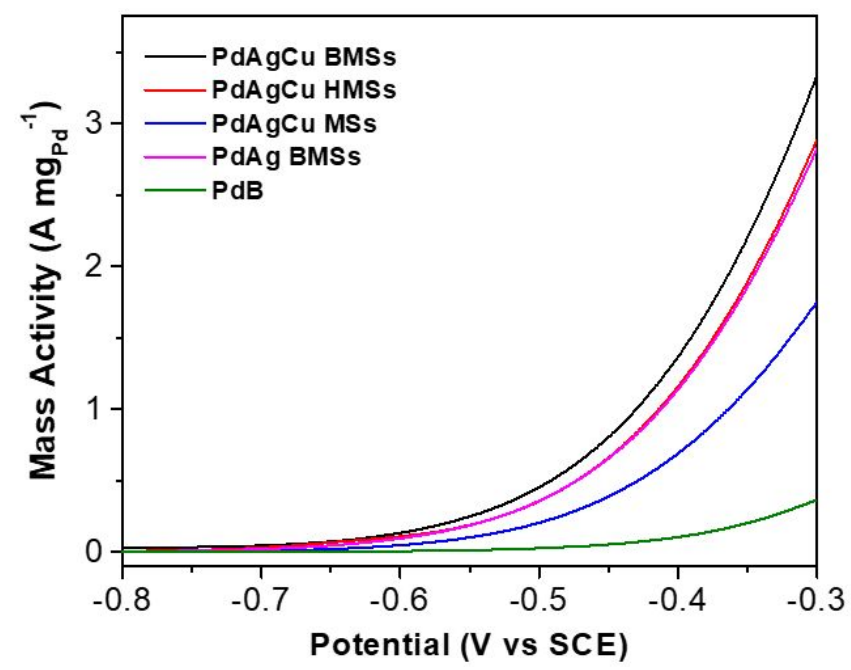

Figure S31 Onset potentials of trimetallic PdAgCu BMSs, HMSs and MSs, bimetallic PdAg BMSs, commercial PdB collected in $1.0 \mathrm{M} \mathrm{KOH}$ and $1.0 \mathrm{M}$ ethanol with a scan rate of $50 \mathrm{mV} \mathrm{s}^{-1}$. 

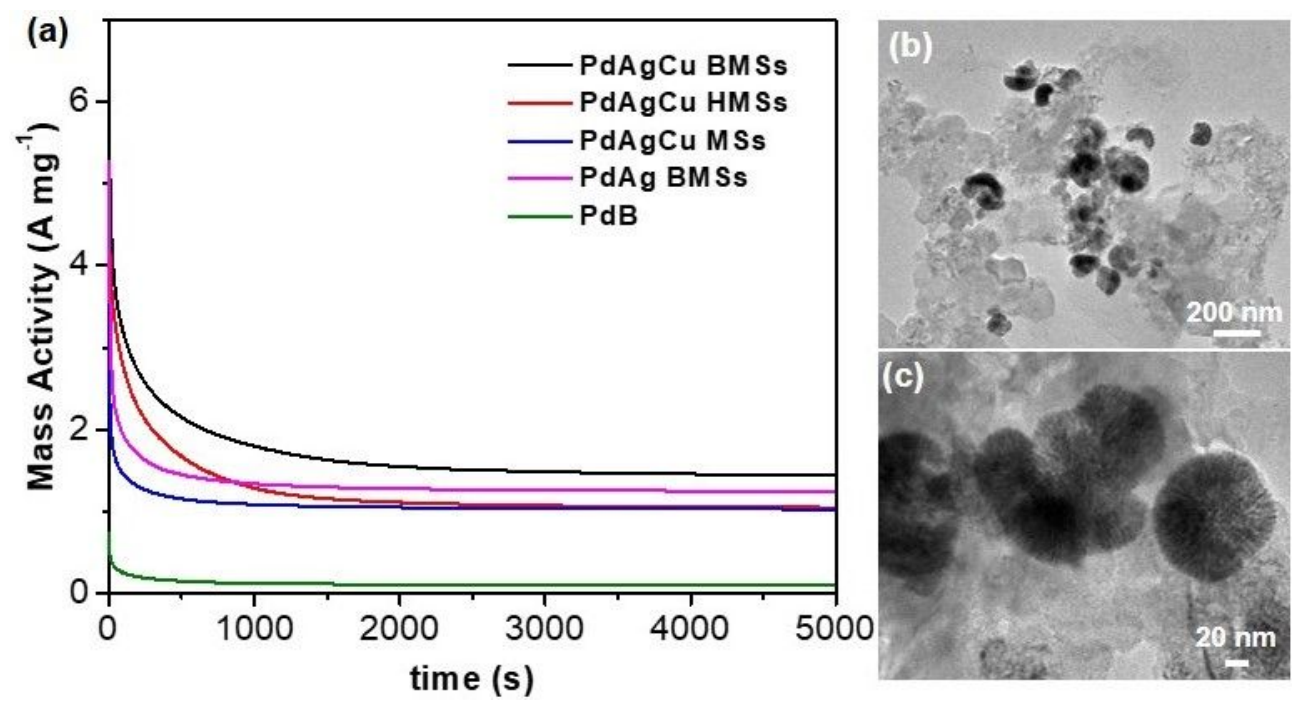

Figure S32 (a) Electrocataltyic i-t curves of the PdAgCu BMSs, HMSs and MSs, and PdAg BMSs and commercial PdB collected in 1.0 M KOH and 1.0 M ethanol. (b, c) TEM images of PdAgCu BMSs after i-t test.

Notes for Figure S32: The bowl-shaped nanostructure was mostly retained after stability test, further highlighting the structural stability of the BMSs for the electrocatalysis.
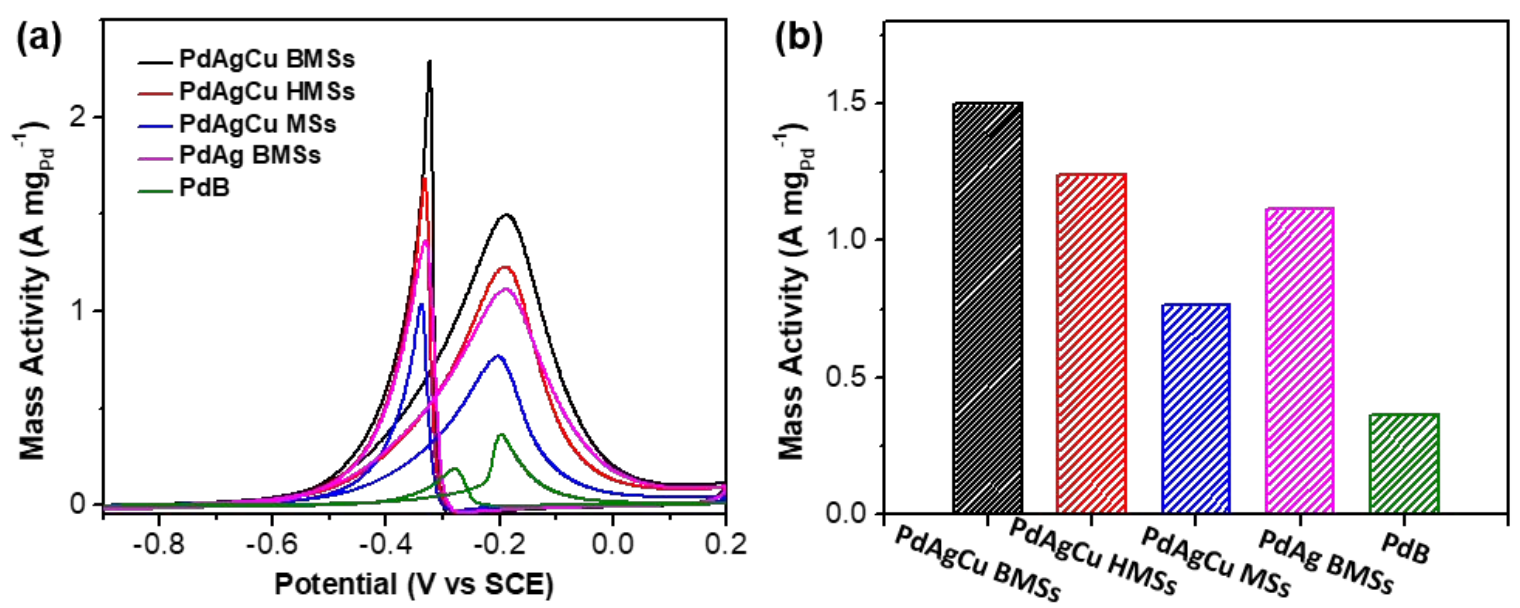

Figure S33 Methanol electrooxidation. CV curves and corresponding mass activities of the $\mathrm{PdAgCu}$ BMSs, HMSs and MSs, and PdAg BMSs and commercial PdB collected in $1.0 \mathrm{M} \mathrm{KOH}$ and $1.0 \mathrm{M}$ methanol. 

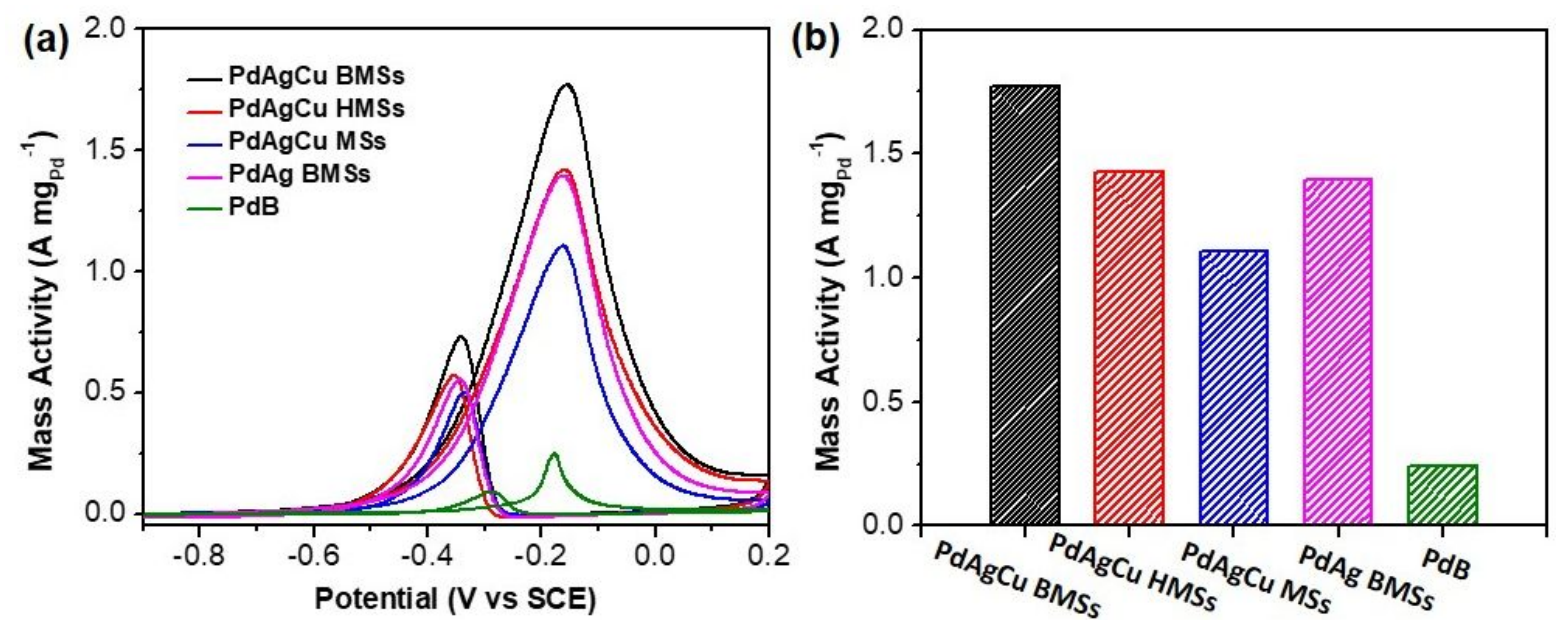

Figure S34 Glycerol electrooxidation. CV curves and corresponding mass activities of the $\mathrm{PdAgCu}$ BMSs, HMSs and MSs, and PdAg BMSs and commercial PdB collected in $1.0 \mathrm{M} \mathrm{KOH}$ and $0.1 \mathrm{M}$ glycerol.
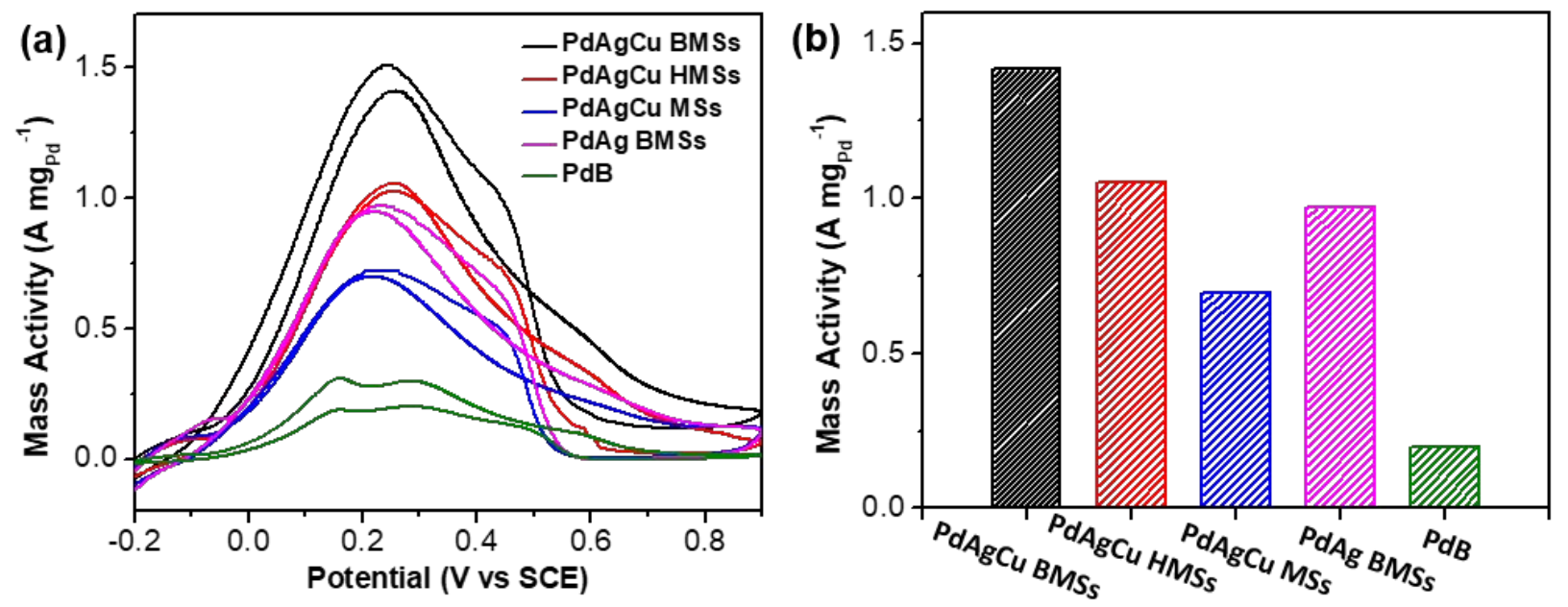

Figure S35 Formic acid electrooxidation. CV curves and corresponding mass activities of the $\mathrm{PdAgCu}$ BMSs, HMSs and MSs, and PdAg BMSs and commercial PdB collected in $0.5 \mathrm{M} \mathrm{H}_{2} \mathrm{SO}_{4}$ and $1.0 \mathrm{M}$ formic acid. 

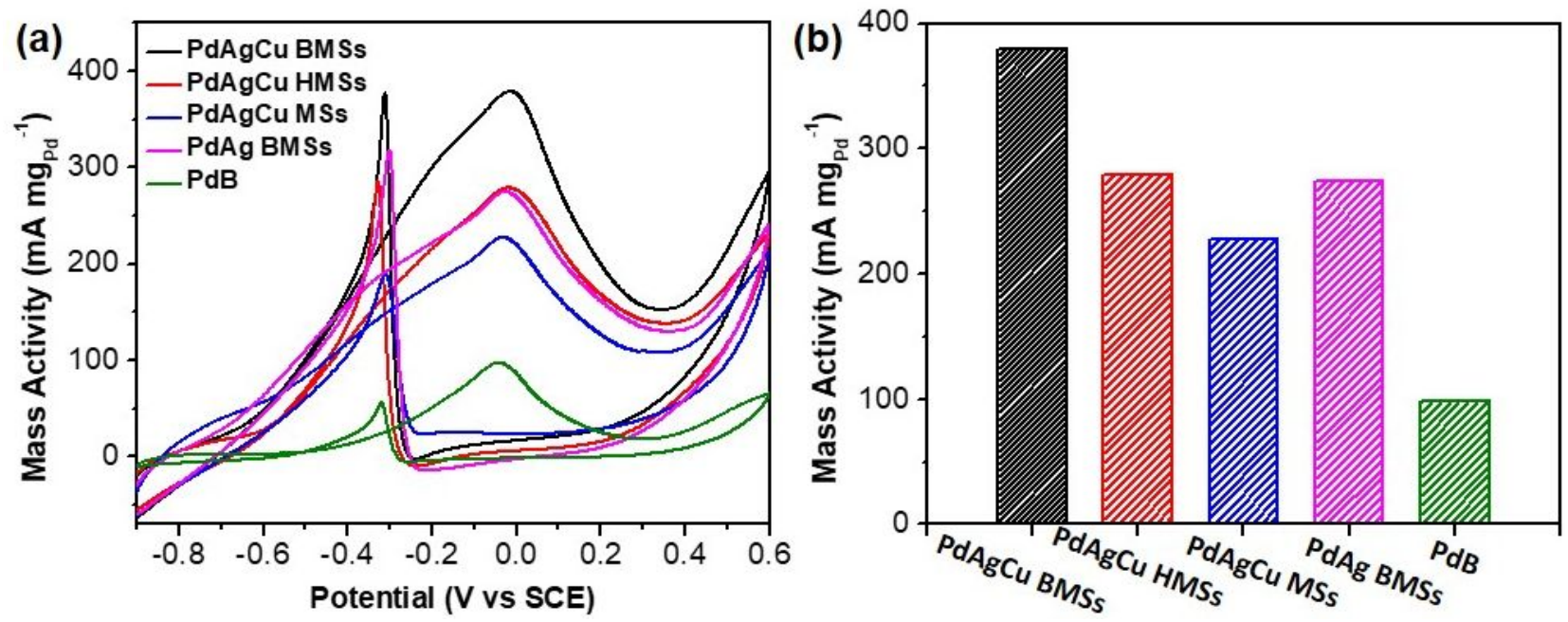

Figure S36 Glucose electrooxidation. CV curves and corresponding mass activities of the PdAgCu BMSs, HMSs and MSs, and PdAg BMSs and commercial PdB collected in $0.1 \mathrm{M} \mathrm{NaOH}$ and $0.1 \mathrm{M}$ glucose. 
Table S1 Summary of $\mathrm{PdAgCu}$ nanostructures obtained under various synthesis parameters.

\begin{tabular}{|c|c|c|c|c|c|c|c|c|c|}
\hline \multicolumn{7}{|c|}{ Synthesis parameters } & \multicolumn{3}{|c|}{ PdAgCu nanostructures } \\
\hline $\begin{array}{c}\text { DODAC } \\
\text { concentration } \\
(\mathrm{mg} / \mathrm{mL})\end{array}$ & $\begin{array}{l}\text { metal } \\
\text { precursor } \\
\text { content }\end{array}$ & $\mathrm{pH}$ & temperature & surfactants & $\begin{array}{l}\text { ethanol } \\
\text { content }\end{array}$ & $\begin{array}{l}\text { reducing } \\
\text { agents }\end{array}$ & shape & $\begin{array}{l}\text { Size } \\
(\mathrm{nm})\end{array}$ & geometry \\
\hline 0 & $10 \mathrm{mM}$ & 7.11 & $25^{\circ} \mathrm{C}$ & DODAC & $20 \mu \mathrm{L}$ & $\mathrm{AA}$ & Nanoparticles & - & - \\
\hline 0.05 & $10 \mathrm{mM}$ & 7.11 & $25^{\circ} \mathrm{C}$ & DODAC & $20 \mu \mathrm{L}$ & $\mathrm{AA}$ & HMSs & $\sim 138$ & Symmetric \\
\hline 0.1 & $10 \mathrm{mM}$ & 7.11 & $25^{\circ} \mathrm{C}$ & DODAC & $20 \mu \mathrm{L}$ & $\mathrm{AA}$ & HMSs & $\sim 116$ & Symmetric \\
\hline 0.15 & $10 \mathrm{mM}$ & 7.11 & $25^{\circ} \mathrm{C}$ & DODAC & $20 \mu \mathrm{L}$ & $\mathrm{AA}$ & HMSs & $\sim 100$ & Symmetric \\
\hline 0.3 & $10 \mathrm{mM}$ & 7.11 & $25^{\circ} \mathrm{C}$ & DODAC & $20 \mu \mathrm{L}$ & $\mathrm{AA}$ & BMS-g & $\sim 98$ & Symmetric \\
\hline 0.6 & $10 \mathrm{mM}$ & 7.11 & $25^{\circ} \mathrm{C}$ & DODAC & $20 \mu \mathrm{L}$ & $\mathrm{AA}$ & BMS-7/8 & $\sim 108$ & Asymmetric \\
\hline 0.9 & $10 \mathrm{mM}$ & 7.11 & $25^{\circ} \mathrm{C}$ & DODAC & $20 \mu \mathrm{L}$ & $\mathrm{AA}$ & BMS-6/8 & $\sim 86$ & Asymmetric \\
\hline 1.2 & $10 \mathrm{mM}$ & 7.11 & $25^{\circ} \mathrm{C}$ & DODAC & $20 \mu \mathrm{L}$ & AA & BMS-5/8 & $\sim 91$ & Asymmetric \\
\hline 1.5 & $10 \mathrm{mM}$ & 7.11 & $25^{\circ} \mathrm{C}$ & DODAC & $20 \mu \mathrm{L}$ & $\mathrm{AA}$ & BMS-4/8 & $\sim 90$ & Asymmetric \\
\hline 2.0 & $10 \mathrm{mM}$ & 7.11 & $25^{\circ} \mathrm{C}$ & DODAC & $20 \mu \mathrm{L}$ & AA & BMS-3/8 & $\sim 63$ & Asymmetric \\
\hline 2.5 & $10 \mathrm{mM}$ & 7.11 & $25^{\circ} \mathrm{C}$ & DODAC & $20 \mu \mathrm{L}$ & AA & BMS-2/8 & $\sim 51$ & Asymmetric \\
\hline 3.0 & $10 \mathrm{mM}$ & 7.11 & $25^{\circ} \mathrm{C}$ & DODAC & $20 \mu \mathrm{L}$ & $\mathrm{AA}$ & BMS-1/8 & $\sim 47$ & Asymmetric \\
\hline 4.0 & $10 \mathrm{mM}$ & 7.11 & $25^{\circ} \mathrm{C}$ & DODAC & $20 \mu \mathrm{L}$ & AA & Irregular shapes & - & - \\
\hline 1.5 & $2 \mathrm{mM}$ & 7.11 & $25^{\circ} \mathrm{C}$ & DODAC & $20 \mu \mathrm{L}$ & $\mathrm{AA}$ & $\begin{array}{l}\text { Bowl-shaped } \\
\text { Nanostructure }\end{array}$ & - & Asymmetric \\
\hline 1.5 & $5 \mathrm{mM}$ & 7.11 & $25^{\circ} \mathrm{C}$ & DODAC & $20 \mu \mathrm{L}$ & AA & $\begin{array}{l}\text { Bowl-shaped } \\
\text { Nanostructure } \\
\text { and BMS }\end{array}$ & - & - \\
\hline 1.5 & $10 \mathrm{mM}$ & 7.11 & $25^{\circ} \mathrm{C}$ & DODAC & $20 \mu \mathrm{L}$ & $\mathrm{AA}$ & BMS-4/8 & $\sim 118$ & Asymmetric \\
\hline 1.5 & $20 \mathrm{mM}$ & 7.11 & $25^{\circ} \mathrm{C}$ & DODAC & $20 \mu \mathrm{L}$ & $\mathrm{AA}$ & $\begin{array}{l}\text { HMS-Shaped } \\
\text { Nanostructure }\end{array}$ & $\sim 55$ & $\begin{array}{c}\text { Almost } \\
\text { Symmetric }\end{array}$ \\
\hline 1.5 & $10 \mathrm{mM}$ & 5.86 & $25^{\circ} \mathrm{C}$ & DODAC & $20 \mu \mathrm{L}$ & AA & $\begin{array}{l}\text { Mesoporous } \\
\text { Nanospheres }\end{array}$ & $\sim 56$ & Symmetric \\
\hline 1.5 & $10 \mathrm{mM}$ & 6.07 & $25^{\circ} \mathrm{C}$ & DODAC & $20 \mu \mathrm{L}$ & AA & BMS-6/8 & $\sim 60$ & Asymmetric \\
\hline 1.5 & $10 \mathrm{mM}$ & 6.63 & $25^{\circ} \mathrm{C}$ & DODAC & $20 \mu \mathrm{L}$ & $\mathrm{AA}$ & BMS-5/8 & $\sim 65$ & Asymmetric \\
\hline 1.5 & $10 \mathrm{mM}$ & 7.11 & $25^{\circ} \mathrm{C}$ & DODAC & $20 \mu \mathrm{L}$ & $\mathrm{AA}$ & BMS-4/8 & $\sim 118$ & Asymmetric \\
\hline 1.5 & $10 \mathrm{mM}$ & 7.56 & $25^{\circ} \mathrm{C}$ & DODAC & $20 \mu \mathrm{L}$ & AA & BMS-3/8 & $\sim 110$ & Asymmetric \\
\hline 1.5 & $10 \mathrm{mM}$ & 8.62 & $25^{\circ} \mathrm{C}$ & DODAC & $20 \mu \mathrm{L}$ & $\mathrm{AA}$ & BMS-2/8 & $\sim 107$ & Asymmetric \\
\hline 1.5 & $10 \mathrm{mM}$ & 7.11 & $0^{\circ} \mathrm{C}$ & DODAC & $20 \mu \mathrm{L}$ & $\mathrm{AA}$ & BMS-2/8 & $\sim 98$ & Asymmetric \\
\hline 1.5 & $10 \mathrm{mM}$ & 7.11 & $25^{\circ} \mathrm{C}$ & DODAC & $20 \mu \mathrm{L}$ & $\mathrm{AA}$ & BMS-4/8 & $\sim 118$ & Asymmetric \\
\hline 1.5 & $10 \mathrm{mM}$ & 7.11 & $50{ }^{\circ} \mathrm{C}$ & DODAC & $20 \mu \mathrm{L}$ & AA & BMS & $\sim 128$ & Asymmetric \\
\hline
\end{tabular}




\begin{tabular}{|c|c|c|c|c|c|c|c|c|c|}
\hline 1.5 & $10 \mathrm{mM}$ & 7.11 & $75^{\circ} \mathrm{C}$ & DODAC & $20 \mu \mathrm{L}$ & AA & $\begin{array}{c}\text { BMS and } \\
\text { Nanowires }\end{array}$ & - & - \\
\hline 1.5 & $10 \mathrm{mM}$ & 7.11 & $95^{\circ} \mathrm{C}$ & DODAC & $20 \mu \mathrm{L}$ & AA & $\begin{array}{c}\text { Nanowires } \\
\text { and } \\
\text { Nanoparticles }\end{array}$ & - & - \\
\hline 1.5 & $10 \mathrm{mM}$ & 7.11 & $25^{\circ} \mathrm{C}$ & $\mathrm{C}_{16} \mathrm{TAC}$ & $20 \mu \mathrm{L}$ & AA & $\begin{array}{l}\text { Mesoporous } \\
\text { Nanospheres }\end{array}$ & $\sim 56$ & Symmetric \\
\hline 1.5 & $10 \mathrm{mM}$ & 7.11 & $25^{\circ} \mathrm{C}$ & $\mathrm{C}_{22} \mathrm{TAC}$ & $20 \mu \mathrm{L}$ & AA & Nanosheets & - & - \\
\hline 1.5 & $10 \mathrm{mM}$ & 7.11 & $25^{\circ} \mathrm{C}$ & SDS & $20 \mu \mathrm{L}$ & $\mathrm{AA}$ & Irregular shapes & - & - \\
\hline 1.5 & $10 \mathrm{mM}$ & 7.11 & $25^{\circ} \mathrm{C}$ & F127 & $20 \mu \mathrm{L}$ & AA & $\begin{array}{l}\text { Nanoparticle } \\
\text { Aggregates }\end{array}$ & - & - \\
\hline 1.5 & $10 \mathrm{mM}$ & 7.11 & $25^{\circ} \mathrm{C}$ & PVP & $20 \mu \mathrm{L}$ & AA & $\begin{array}{l}\text { Nanoparticle } \\
\text { Aggregates }\end{array}$ & - & - \\
\hline 1.5 & $10 \mathrm{mM}$ & 7.11 & $25^{\circ} \mathrm{C}$ & DODAC & $\mathbf{0}$ & $\mathrm{AA}$ & BMS-2/8 & $\sim 146$ & Asymmetric \\
\hline 1.5 & $10 \mathrm{mM}$ & 7.11 & $25^{\circ} \mathrm{C}$ & DODAC & $10 \mu \mathrm{L}$ & $\mathrm{AA}$ & BMS-3/8 & $\sim 124$ & Asymmetric \\
\hline 1.5 & $10 \mathrm{mM}$ & 7.11 & $25^{\circ} \mathrm{C}$ & DODAC & $20 \mu \mathrm{L}$ & $\mathrm{AA}$ & BMS-4/8 & $\sim 118$ & Asymmetric \\
\hline 1.5 & $10 \mathrm{mM}$ & 7.11 & $25^{\circ} \mathrm{C}$ & DODAC & $50 \mu \mathrm{L}$ & AA & BMS-5/8 & $\sim 123$ & Asymmetric \\
\hline 1.5 & $10 \mathrm{mM}$ & 7.11 & $25^{\circ} \mathrm{C}$ & DODAC & $100 \mu \mathrm{L}$ & $\mathrm{AA}$ & HMS & $\sim 107$ & Symmetric \\
\hline 1.5 & $10 \mathrm{mM}$ & 7.11 & $25^{\circ} \mathrm{C}$ & DODAC & $0.5 \mathrm{~mL}$ & $\mathrm{AA}$ & $\begin{array}{l}\text { Mesoporous } \\
\text { Nanospheres }\end{array}$ & $\sim 93$ & Symmetric \\
\hline 1.5 & $10 \mathrm{mM}$ & 7.11 & $25^{\circ} \mathrm{C}$ & DODAC & $2.0 \mathrm{~mL}$ & $\mathrm{AA}$ & $\begin{array}{l}\text { Mesoporous } \\
\text { Nanospheres }\end{array}$ & $\sim 71$ & Symmetric \\
\hline 1.5 & $10 \mathrm{mM}$ & 7.11 & $25^{\circ} \mathrm{C}$ & DODAC & $4.0 \mathrm{~mL}$ & $\mathrm{AA}$ & $\begin{array}{l}\text { Nanoparticle } \\
\text { Aggregates }\end{array}$ & - & - \\
\hline 1.5 & $10 \mathrm{mM}$ & 7.11 & $25^{\circ} \mathrm{C}$ & DODAC & $20 \mu \mathrm{L}$ & $\mathbf{N}_{2} \mathbf{H}_{4}$ & Nanowires & - & - \\
\hline 1.5 & $10 \mathrm{mM}$ & 7.11 & $25^{\circ} \mathrm{C}$ & DODAC & $20 \mu \mathrm{L}$ & $\mathrm{NaH}_{2} \mathrm{PO}_{2}$ & Nanowires & - & - \\
\hline 1.5 & $10 \mathrm{mM}$ & 7.11 & $25^{\circ} \mathrm{C}$ & DODAC & $20 \mu \mathrm{L}$ & $\mathrm{NaBH}_{4}$ & Nanoparticles & - & - \\
\hline
\end{tabular}


Table S2. Summarization of electrochemical EOR performance of different Pd-based electrocatalysts in alkaline solution.

\begin{tabular}{|c|c|c|c|c|}
\hline \multirow[t]{2}{*}{ Electrocatalyst } & \multicolumn{2}{|c|}{ Electrolyte } & \multirow{2}{*}{$\begin{array}{l}\text { Peak current density } \\
\text { from CV }\left(\mathrm{mA} \mathrm{mg}^{-1}\right) \\
50 \mathrm{mV} \mathrm{s}^{-1}\end{array}$} & \multirow[t]{2}{*}{ Reference } \\
\hline & Ethanol & $\mathrm{KOH}$ & & \\
\hline $\begin{array}{c}\text { PdAgCu BMS- } \\
4 / 8\end{array}$ & $1 \mathrm{M}$ & $1 \mathrm{M}$ & 6360 & This work \\
\hline $\begin{array}{l}\text { PdAgCu hollow } \\
\text { mesospheres }\end{array}$ & $1 \mathrm{M}$ & $1 \mathrm{M}$ & 5140 & ACS Cent. Sci. 2018, 4, 1412 \\
\hline $\begin{array}{c}\mathrm{PdAgCu} \\
\text { mesospheres }\end{array}$ & $1 \mathrm{M}$ & $1 \mathrm{M}$ & 4640 & Chem. Sci. 2019, 10, 1986 \\
\hline $\begin{array}{l}\text { Au@PdAuCu } \\
\text { mesospheres }\end{array}$ & $1 \mathrm{M}$ & $1 \mathrm{M}$ & 3990 & Green Chem. 2019, C9GC00263D \\
\hline $\begin{array}{l}\text { PdNi Hollow } \\
\text { Nanospheres }\end{array}$ & $1 \mathrm{M}$ & $1 \mathrm{M}$ & 3630 & $\begin{array}{c}\text { Angew. Chem. Int. Ed. 2015, 54, } \\
1310\end{array}$ \\
\hline $\mathrm{Pd}_{4} \mathrm{Au}_{1}-\mathrm{P} / \mathrm{CNT}$ & $1 \mathrm{M}$ & $1 \mathrm{M}$ & 2296 & J. Catal. 2017, 353, 256 \\
\hline $\begin{array}{l}\text { PdCo nanotube } \\
\text { /carbon cloth }\end{array}$ & $1 \mathrm{M}$ & $1 \mathrm{M}$ & $\sim 1500$ & $\begin{array}{c}\text { Angew. Chem. Int. Ed. 2015, } 54, \\
3669\end{array}$ \\
\hline $\begin{array}{c}\text { Au@Pd } \\
\text { Nanorods }\end{array}$ & $1 \mathrm{M}$ & $1 \mathrm{M}$ & 2920 & Adv. Mater. 2017, 29, 1701331 \\
\hline $\mathrm{Pd} / \mathrm{Au} / \mathrm{C}$ & $1 \mathrm{M}$ & $1 \mathrm{M}$ & $\sim 850$ & J. Power Source 2009, 187, 80 \\
\hline $\begin{array}{c}\mathrm{PdCu}_{2} \\
\text { Nanoparticles }\end{array}$ & $1 \mathrm{M}$ & $1 \mathrm{M}$ & 1600 & $\begin{array}{c}\text { ACS Appl. Mater. Interfaces 2016, } \\
8,34497\end{array}$ \\
\hline $\begin{array}{l}\text { Pd nanowire } \\
\text { arrays }\end{array}$ & $1 \mathrm{M}$ & $1 \mathrm{M}$ & 308 & Adv. Mater. 2007, 19, 4256-4259 \\
\hline $\begin{array}{l}\text { PdAg hollow } \\
\text { nanoflowers }\end{array}$ & $1 \mathrm{M}$ & $1 \mathrm{M}$ & 1616 & Chem. Eur. J. 2016, 22, 16642 \\
\hline $\mathrm{Pd}_{1} \mathrm{Ag}_{1} \mathrm{NPs} / \mathrm{GO}$ & $1 \mathrm{M}$ & $1 \mathrm{M}$ & 1601 & J. Power Sources 2014, 263, 13. \\
\hline $\begin{array}{c}\text { PdCo/N-doped } \\
\text { Cabon }\end{array}$ & $1 \mathrm{M}$ & $1 \mathrm{M}$ & 1250 & J. Mater. Chem. A 2017, 5, 10876 \\
\hline $\begin{array}{c}\mathrm{PdCu} \\
\text { nanocapsules }\end{array}$ & $1 \mathrm{M}$ & $1 \mathrm{M}$ & 1140 & Nanoscale 2014, 6, 2768 \\
\hline $\begin{array}{c}\mathrm{Pd} / \mathrm{Ru} \\
\text { nanodendrites }\end{array}$ & $1 \mathrm{M}$ & $1 \mathrm{M}$ & 1150 & Nanoscale 2015, 7, 12445 \\
\hline $\mathrm{Pd}-\mathrm{NiCoO} \times \mathrm{C}$ & $1 \mathrm{M}$ & $0.5 \mathrm{M}$ & $\sim 450$ & J. Power Sources 2015, 273, 631 \\
\hline $\begin{array}{c}\mathrm{Pd}_{7} / \mathrm{Ru}_{1} \\
\text { nanodendrites }\end{array}$ & $1 \mathrm{M}$ & $1 \mathrm{M}$ & $\sim 1150$ & Nanoscale 2015, 7, 12445 \\
\hline $\mathrm{Pd}_{21} \mathrm{Cu}_{79}$ & $0.5 \mathrm{M}$ & $0.5 \mathrm{M}$ & 1782 & Langmuir 2013, 29, 9249 \\
\hline $\begin{array}{c}\text { Au@AgPd } \\
\text { Nanoparticles }\end{array}$ & $1 \mathrm{M}$ & $1 \mathrm{M}$ & 1160 & J. Phys. Chem. C 2015, 119, 18434 \\
\hline $\begin{array}{l}\text { 10.8-nm-thick } \\
\text { PdPt NWs }\end{array}$ & $1 \mathrm{M}$ & $1 \mathrm{M}$ & 940 & Adv. Mater. 2012, 24, 2326 \\
\hline
\end{tabular}

